Please cite this paper as follows:

Javier Mendoza-Vizcaino, Muhammad Raza, Andreas Sumper, Francisco Díaz-González, Samuel Galceran-Arellano,

Integral approach to energy planning and electric grid assessment in a renewable energy technology integration for a 50/50 target applied to a small island,

Applied Energy,

Volumes 233-234,

2019,

Pages 524-543,

ISSN 0306-2619,

https://doi.org/10.1016/j.apenergy.2018.09.109.

(http://www.sciencedirect.com/science/article/pii/S0306261918314168) 


\title{
Integral Approach to Energy Planning and Electric Grid Assessment in a Renewable Energy Technology Integration for a 50/50 Target Applied to a Small Island
}

\author{
Javier Mendoza-Vizcaino ${ }^{1 *}$, Muhammad Raza ${ }^{1}$, Andreas Sumper ${ }^{1}$, Francisco \\ Díaz-González ${ }^{1}$, Samuel Galceran-Arellano ${ }^{1}$ \\ ${ }^{1}$ Centre d'Innovaciò Tecnològica en Convertidors Estàtics i Accionaments (CITCEA-UPC), Departament \\ d'Enginyeria Elèctrica, Universitat Politècnica de Catalunya, ETS d'Enginyeria Industrial de Barcelona, \\ Spain. www.citcea.upc.edu
}

\begin{abstract}
This paper presents an energy planning, a grid assessment, and an economic analysis, considering three growing scenarios (Low, Base and High) in the electricity consumption, to supply the energy demand for a hybrid power system (Photovoltaics/Wind/Diesel/Battery) on a small island by 2050. The main aim of this study is to present a methodology to optimize and reduce the backup time of the battery bank, included from the hybrid power generation system selected. Also, it will compare four different battery technologies, simultaneously, without changes in the renewable energy targets settled in 50\% until 2050 and without changes in the safe continuous operation of the grid. The methodology includes a grid assessment analysis to obtain a reliable, strong and safe operation response based on the grid code parameters, even in case of disturbance.

In the proposed methodology the analysis is developed on the basis of the use of two simulation model tools. The First simulation model tool determines the optimal values of variables that the system designer controls, such as the mix of components (Photovoltaics/Wind/Diesel/Battery) that make up the system and the size or quantity of each variable. This model uses the multiyear analysis based on a time-domain simulation run at the energyflow level with discrete time-steps of 1 hour. The Second simulation model tool assumes all the variables and parameters on the grid as constants during the period of time analyzed. The power flow is analyzed through a programming language command script function and reflects the system response at a specific time with given specific variables and parameters. The final technical proposal and its financial analysis are obtained applying and validating this methodology on a small island, as well as, the selection of the system to be installed for the renewable electricity generation. The electric grid modifications and reinforcements through the years until 2050, according to the grid code and the renewable energy targets settled for the island's electric power system are included.
\end{abstract}

Keywords:

electrical networking planning; energy planning; grid assessment; hybrid system; small island; renewable energy;

${ }^{*}$ Correspondence: francisco.javier.mendoza@estudiant.upc.edu; Tel.: +34 934054245 


\section{Introduction: renewable electricity integration on small islands}

Nowadays there are several renewable generation technologies for the carbon-free emission electricity production. For the small islands with less than 100,000 inhabitants [1, the integration of these Renewable Energy Technologies (RETs) is an environmentally friendly option to reduce the fuel cost of its electricity production. However, the use of the RETs in an isolated or weak electric grid, produces impacts on the grid's operation, due to the variability of the energy generation over the period of time. The nature of energy generation variability depends on the resources that are being used to supply the load. Alqurashi et al. 22 provide a technical overview of the advances in this area to solve some of these uncertainties. Maleki et al. [3] analyzed a resource and load uncertainties in a hybrid renewable energy system. In a hybrid generation system (Renewable + Diesel + Batteries), in order to supply all the energy production, the system must coordinate this renewable production with the diesel generator production to reduce the fossil fuel consumption. The network should be able to intake the renewable energy to fulfil the targets according to the agreement on the political goals of any country, region or city. An example of this, various studies from literature show that these renewable energy targets go from $50 \%$ globally in islands [1, $50 \%$ in Cozumel Island, Mexico [4], and 65\% in Graciosa Island, Azores [5] to 100\% in Canary Islands, Spain [6], 100\% in Åland Islands, Finland [7, 100\% in Cook Islands [8] and 100\% in Mauritius Island [9]. The hybrid system must supply the power demand in every step of time designed with the lowest cost of production. The constraints and targets through the sensitivity analysis chosen, like cost reductions, fuel price variations, inflation rate variations and efficiency variations, can reduce the uncertainty threshold in the final decision to obtain the hybrid power system to install.

Several studies are been presented to integrate the renewable electricity generation and coordinate the energy balance and grid response for an isolated or weak electric grid in a hybrid generation system. Sigrist et al. [10, Zhang et al. [11, Obi et al. [12], Dufo-López et al. [13, Kwon et al. [14, and Szabó et al. [15] analyzed technically and economically the renewable energy integration including the energy storage system. Other studies have been developed with an emphasis in technical analysis for the renewable electricity integration, as can be seen in the work of Adefarati and Basal [16], Wijayatunga et al. [17] in Maldives Islands, Koepke and Groh [18 in Bangladesh, and Sheng et al. [19]. In this last work, the marine current turbine works together with ocean compressed energy storage. Some works propose the use of the energy storage system for the system planning, the dispatch operation, the frequency regulation and to provide the spinning reserve needed. An example of this are those studied by Shang et al. [20], Miguel et al. [21] in Madeira Island, Setas et al. 22] in Terceira Island, and Fleer and Stenzel [23. Or simply analyzing the battery degradation process [24] or analyzing the risk in the use of the battery system (Lithium-ion) in a grid scale [25]. Finally, there are technical studies to integrate the renewable electricity generation technology with the energy storage system, madden according to the political framework and strategies for a country. Also, to develop those political frameworks and strategies, in order to achieve a better renewable generation technology integration. These works are from Taliotis et al. [26], Taibi et al. [27], Simoes et al. [28], Lin et al. [29], and Staffell and Rustomji [30]. The work of G.M. Shafiulla [31] propose the techno-economic and environmental prospects of 
renewable energy integration in the Capricornia region of Queensland, Australia. This work includes a load management system by which utilities can manage customer load demand efficiently.

Other similar works can be found. For example, Gan et al. 32 developed an optimization model to operate the diesel generator from a hybrid power system in an optimum way. Muruganantham et al. 33] describes the state of art in various load flow methods used to analyze the parameters of the distribution network. Therefore, the contribution of this study is a methodology for an integral energy planning, a grid assessment and an economic analysis, considering three growing scenarios (Low, Base and High) in the electricity consumption for a hybrid power system (Photovoltaics/Wind/Diesel/Battery) on a small island through time until 2050. Starting in the energy planning, this methodology establishes the initial integration of the renewable technology until the grid assessment and its safe operation and response, including the grid reinforcements through the years and the financial analysis (always fulfilling the renewable energy targets). The results in the literature reviewed partially do this, but most of them do not do it as an integral study. So, in this paper, the holistic impact of the integration of a new renewable energy technology configuration through the years on the dynamic behaviour and stability of the existing power system is systematically analyzed. The hybrid energy system analyzed deals with the energy planning and dynamic and stability simulations in an hourly time resolution through a DIgSILENT Programming Language (DPL) command script function for each year. This hourly combination can validate the energy and grid planning scenarios in the short-term dynamic simulations on frequency and voltage stability, and for a long-term planning scenarios analysis until 2050, for instance. Also, this paper has the aim to optimize and to reduce the battery bank backup time and to compare four different battery technologies. This should not present any changes in the renewable energy targets settled for the safe continuous operation of the grid. The results and response of this hybrid power system (Photovoltaics/Wind/Diesel/Battery) proposed will be compared always against the results and response of use only a fossil fuel power system (only Turbogas machines burning Diesel), in order to supply the electricity demand in the growing scenarios through the years until 2050.

The content is structured in Seven Sections. The First Section is the introduction and the Second Section explains the methodology, which is integrated into 4 phases on a small island. The Third Section explains the selection of an existing small island, Cozumel Island, in Mexico as a study case to apply and validate this methodology and to start the energy planning, the grid assessment and the economic analysis. This proposal will compare the use of only fossil fuel vs. the use of a hybrid system to satisfy the electric demand through three growing scenarios until 2050. This date was selected according to the National Energy Planning for Cozumel Island in Mexico. In the Fourth Section, the steady-state analysis and the dynamic stability analysis are elaborated, including the power system response as well. This is taking into account all the electric grid's modifications and reinforcements to be done. Then, the final complete power system will be selected as the system to be installed on the Island. By an economic analysis formulated at Fifth Section, the final Initial Capital Cost (ICC), the Net Present Value (NPV), the Internal Return Rate (IRR) and the Levelized Cost Of Energy (LCOE) for the complete power system are obtained. The Fifth Section includes the ICC of the hybrid generation system, and the ICC of the electric grid proposed and modified. The discussion is in the Sixth Section and the conclusions are highlighted in 
the Seventh Section. At the end of this document, the acknowledgement and references are included.

\section{Methodology to assess an integral approach to the renewable energy planning and the electric grid assessment for a small island}

As the Small Island Development States (SIDS) or Countries are become more renewable in the energy consumption or production, as the Paris Agreement-Status of Ratification shows [34], their national legal framework includes the renewable energy targets to be fulfilled until 2020, 2030 or 2050, for instance. So, this methodology is developed in four phases and the hybrid power system analyzed will supply the electric demand through the years until 2050 (Phase 1). The time-varying profile of load and renewable generation will be compared against the use of only fossil fuel and will analyze the advantages of their integration on the grid. In Phase 2, as result of the simplified system operation analysis (power flow), the electric grid will be modified or reinforced, in order to maintain the system parameters according to the grid code. At this point, the electric system response has to be good enough to fulfil the grid code parameters selected, even in case of disturbance and faults in the grid. As part of Phase 3, these faults and disturbances will show how strong the electric grid response is, if the grid shows weakness in the response, the modifications will improve this response. In Phase 4 the economic analysis for the hybrid power system will be performed, including in the final ICC the cost of the electric grid modifications or reinforcements.

The methodology used to assess a strong grid response when the renewable energy generation is integrated in a small island power system is indicated in Fig. 1. This methodology includes the battery backup time reduction analysis. In the methodology proposed, the data marked in a italic and bold format is the particular data input chosen for this specific study case. To use this methodology on other small islands, just use the specific data from the small island and substitute them in the italic and bold format spaces.

\subsection{PHASE 1 (Renewable electricity integration and batteries backup-time reduction analy- sis)}

Objective: Satisfy the power demand on the small island in order to fulfil the renewable energy targets and constraints for the planning scenarios of electricity consumption growing selected or developed. From a hybrid power system with batteries included, reduce the backup time from the battery bank and compare four different battery technologies simultaneously, as well.

STEP 1. Selection of the initial hybrid system (Photovoltaics/Wind/Diesel/Battery) to analyze and optimize its operation and results.

STEP 2. In this step, the input data to determine the simulation parameters and constrains for the hybrid system analysis to be done in STEP 3 is uploaded. For example: a) A minimum backup time according to the grid code selected of $\mathbf{3 0}$ min from a cold start to a synchronicity running for a diesel machine. b) A Renewable Energy Fraction (REF) integrated in the electric grid of $41.1 \%$ by $2018,45 \%$ by 2024, 51.4\% by 2035, and $\mathbf{5 8 . 9 \%}$ by 2050. This example is in accordance with the National legal framework in Mexico, that includes the renewable energy targets to be fulfilled until 2050. c) A sensitivities variables applied, like a cost reductions, an increasing efficiency, and an 


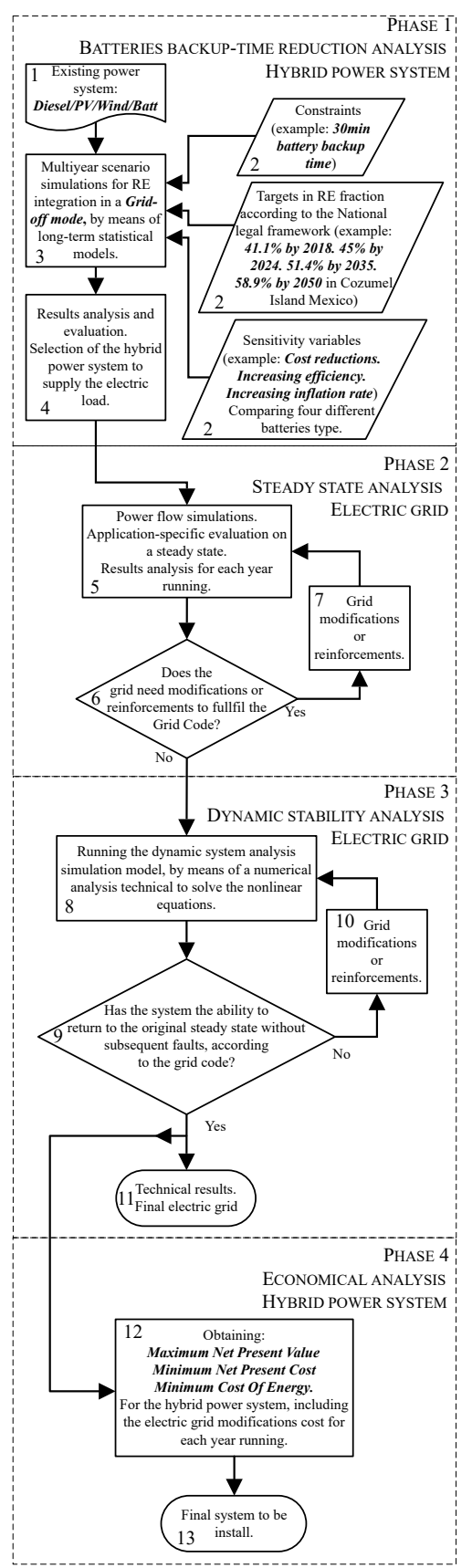

Figure 1: Methodology to analyze the integration of the renewable electricity generation and the electric grid response on a disconnected small island, comparing four different batteries type and reducing their battery backup time.

increasing inflation rate. All this comparing four different batteries type to determine the best performance with the minimum operation cost, using Ion-Lithium, Lead-Acid, Vanadium flow redox, and Zinc-Bromine flow redox.

STEP 3. By means of a long-term statistical model, a deterministic methodology is used to perform time-series simulations. This analysis is made considering the electric system in a grid-off mode or disconnected. In this step, the energy planning and the growing scenarios 
are developed or selected. For this case, the selection of the growing scenarios applied are those analyzed and presented by Mendoza-Vizcaino et al. [4]. The three growing scenarios are: a) Low Scenario; b) Base Scenario, and; c) High Scenario; in the four key years: 2018, 2024, 2035 and 2050 in the electricity consumption and power demanded were taken in consideration from this study.

STEP 4. Regarding the minimum LCOE, the minimum Net Present Cost $(\boldsymbol{N P C})$, and the maximum $\boldsymbol{N P V}$ the analysis and the results evaluation are made to choose the hybrid generation system to be installed on the Island.

\subsection{PHASE 2 (Steady-state analysis)}

Objective: To ensure the reliability and safety of the grid's operation response according to the hourly input data in the simulations on the base of the results obtained in Phase 1.

STEP 5. In this stage, the power flow simulations are executed. The electric system responses must be within a functional range, in order to establish the most suitable operation configuration to keep a reliable, safe and strong grid. The signals to be monitored can be the voltage, the angle, the current flow, the reactive and active power, among others. The power flow analysis of an electric system gives enough information about the grid state in the present time and can use this analysis to have a future operation planning of the system 35 .

STEP 6. In this stage, the analysis of the results from STEP 5 is carried out, this analysis can detect weakness on the grid or a fault on the limits response according to the grid code selected. Therefore, the suggested solution and alternatives or reinforcements to do, while considering monthly and/or yearly load increase or decrease [35] will be done in STEP 7. The working loop between STEP 5 (power flow), STEP 6 (results analysis) and STEP 7 (grid modifications or reinforcements) will be repeated until the parameters of the grids operation response and requirements of the grid code selected will be complimented. If the results fulfil the grid code parameters selected, it must go to STEP 8 (PHASE 3).

STEP 7. In this stage, the changes or suggested solutions and alternatives of reinforcements to do on the electric grid are integrated on it. These changes determine the base of calculus to run the simulations in the new power flow analysis (STEP 5) to obtain the most suitable operation configuration of the grid (STEP 6).

\subsection{PHASE 3 (Dynamic stability analysis)}

Objective: To ensure the stability and safety of the grid's operation response after an event that produces system instability and unbalances.

STEP 8. This analysis is done with the results of the final system chosen in STEP 6. The power system stability depends on the system response in a presence of a short-circuit or by the effects of frequency and voltage values under the varying load or sources conditions. These effects will increase if the supply sources are conforming mostly by renewable energy sources due to its own nature variability. In this document, the dynamic analysis is done so the power system must be able to return to a steady-state after disturbances and to ensure a voltage stability and a frequency stability [36].

STEP 9. As result of the stability analysis, and if the system returns to a steady-state correctly, the procedure will follow STEP 11. If it does not, then the electric grid must be modified to obtain the most suitable operation configuration in STEP 10. 
STEP 10. In this stage, the changes or suggested solutions and alternatives of reinforcements to do on the electric grid are integrated on it. These changes will determine the base of calculus to run the simulations in the stability analysis and obtain a stronger and reliable grid operation response.

STEP 11. The final hybrid power system is shown and this technical results will be the system chosen to install on the Island. Therefore, the economic data obtained from this final system is used together with the economic results from STEP 4 to have a final economical proposal. In PHASE 4, the economic analysis is detailed.

\subsection{PHASE 4 (Economical analysis)}

Objective: To obtain the minimum LCOE and the minimum NPC with the maximum NPV for the hybrid system chosen.

The investment must be able to produce enough profits in order to give back the same amount of the initial capital plus a return flow during the project lifetime [37. This gives reliability and safety to the investment even in the case of severe affectations produced from the natural conditions of the renewable facility's site.

STEP 12. The NPV is the present value of the discounted future cash flow at the end of the project lifetime. This value gives the cash flow saved in comparison with the base case, affected by the capital recovery factor. The more value resulted, the more attractive the investments will be.

STEP 13. The final hybrid power system, including the electric grid, is presented to be installed on the Island as result of the complete analysis done.

\section{Renewable energy integration on a small island: Cozumel Island in Mexico, as a study case}

The RE integration on small islands helps in the de-carbonizing goal for the electricity generation, meanwhile reducing the cost of the fossil fuel spent to supply the electric demand of the electric grid on it. The intermittent production of electricity from Renewable Energy Sources (RES) over the time, produce some uncertainties in the total electricity production. To keep the balance of the system between the renewable energy production and the energy consumption, the fossil fuel generation and the energy storage must be coordinated to guarantee the power system stability. The analysis presented in this paper is done on the base of a hybrid power system already presented by [4] on a small Caribbean island. This small island is placed on the Occidental Caribbean Sea, as Cozumel Island in Mexico (see Fig. 2). Currently, there is not a RES supplying electricity into the electric grid on Cozumel Island, so this work takes the results and data used by [4] to reduce the backup time of the battery bank proposed from $2 \mathrm{~h}$ to $0.5 \mathrm{~h}$ according to the Mexican Grid Code (MGC) [38]. This is done so, in case of a renewable electricity production variation, it is necessary that the system keeps the reliability on the grid, and the battery bank must support the grid balance, while the diesel turbine starts and synchronizes on it. Also, the targets in the $\mathrm{CO}_{2}$ emission reduction, which determine the REF to integrate to the electric grid for each year and scenario, are used. 


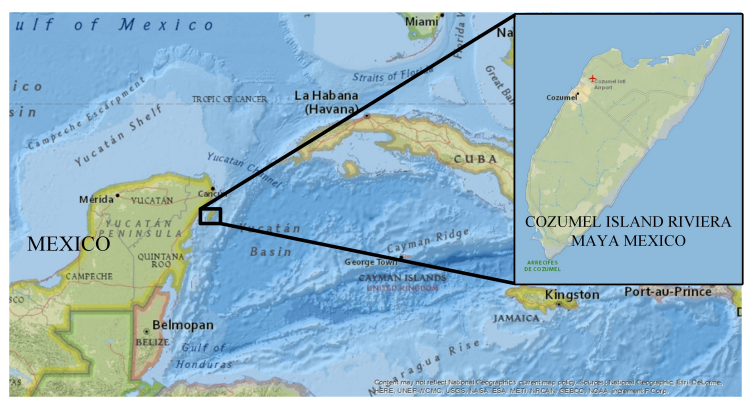

Figure 2: Cozumel Island localization [4]

\subsection{Previous essential information}

All the previous analysis are including the REF factor target fulfilment settled in STEP 2. The wind speed data was obtained from the US Renewable Resource Data Center for the specific area of the WIND site [39] [40] [41]. The Photovoltaic (PV) production is calculated according to the solar radiation incident on the PV array and it was obtained from NASA's Surface Solar Energy Data Set for the specific area of the PV site [39] [40] [42. The storage energy brings safety to the response of the system in case of unbalance between load and generation. It can supply the lack of electricity in the grid according to the size and parameters of the battery bank designed. It can also store the excess electricity production from the overproduction of the RETs or from the minimum electricity production settled on the fossil fuel machine parameters [20] 21] [22] [23]. The power needed to design the minimum size of the battery bank, the maximum power charging and discharging of the battery bank vary according to the specific battery type selected. The backup time or the battery autonomy depends, initially from the technology's characteristics and its control responses [39] [40].

The ratio between the total power generation capacity $(\mathrm{kW})$ and the battery bank capacity $(\mathrm{kW})$ define the number of batteries to install and to obtain the autonomy or the final backup time in hours. To keep the battery charging power and discharging power capacity ratio, the converter must be designed in a relation of 1:1 regarding the battery bank capacity. Depending on the battery type and its operation efficiency, the number of batteries will be modified in order to have the minimum backup time required.

Table 1 shows the electric sector growing perspectives values used to develop the Low Scenario, the Base Scenario and the High Scenario for Cozumel Island from 2018 to 2050 [43].

Table 1: Electric Sector Growing Perspectives for Cozumel Island [43]

\begin{tabular}{c|c|c|c} 
Cozumel Island's Electric Sector \\
Growing Perspectives (\%/yr) \\
\cline { 2 - 4 } & \multicolumn{3}{|c}{ SCENARIO } \\
\cline { 2 - 4 } Power Demand & LOWSE & HIGH \\
\cline { 2 - 4 } Plectricity Consumption & 3.6 & 4.1 & 4.9 \\
\hline \hline
\end{tabular}

These three scenarios were carried out in the Development Program of the National Electric System 2016-2030 (PRODESEN is its Spanish acronym), taking the energy planning predictions in Mexico into consideration. These scenarios were made on the basis of the 
General Economic Policy Criteria for the Initiative of Income Law and the Federation Expenditure Budget Project (CGPE, for its Spanish acronym) 2016. The macroeconomic targets and strategies that are included in these documents are the power demand, the electricity consumption, the fuel prices and the GDP among others.

The results obtained by [4 present the System 2 and System 7 as the systems to be installed on the Island, from the technical and economical perspective, respectively. This proposal combines the $2 \mathrm{MW}$ On-Shore Wind Turbine from System 2, the $3 \mathrm{MW}$ Off-Shore Wind Turbine from System 7 and the PV system joined with the battery bank (see Fig. 5). Table 2 shows the composition of System 2 and System 7 and the final combination to use in this study case.

Table 2: Systems 2 and 7 selected to be integrated in the hybrid system simulations for Cozumel Island 4

\begin{tabular}{lcccc}
\hline Technology Type & PV & Wind & Wind & Wind \\
\hline Company & Generic & GoldWind & Wind to Energy & Sany \\
\hline Power curve type & & III B & III A & S \\
\hline Capacity & $333.33 \mathrm{~kW}$ & $2.5 \mathrm{MW}$ & $3 \mathrm{MW}$ & $2 \mathrm{MW}$ \\
\hline Model & & GW121 & W2E 132 & SE11520 \\
\hline Place to install & On-shore & On-shore & Off-shore & On-shore \\
\hline System 2 & $\sqrt{ }$ & $\sqrt{ }$ & $\sqrt{ }$ & \\
\hline System 7 & $\sqrt{ }$ & & & $\sqrt{ }$ \\
\hline \hline System Selected & $\sqrt{ }$ & & $\sqrt{ }$ & $\sqrt{ }$ \\
\hline \hline
\end{tabular}

The maximum power demanded and the electricity consumed for each year and scenario analyzed for Cozumel Island are shown in Fig. 3. The REF to be integrated on the electric grid for each year and scenario analyzed is indicated in STEP 2 of the methodology. Fig. 4

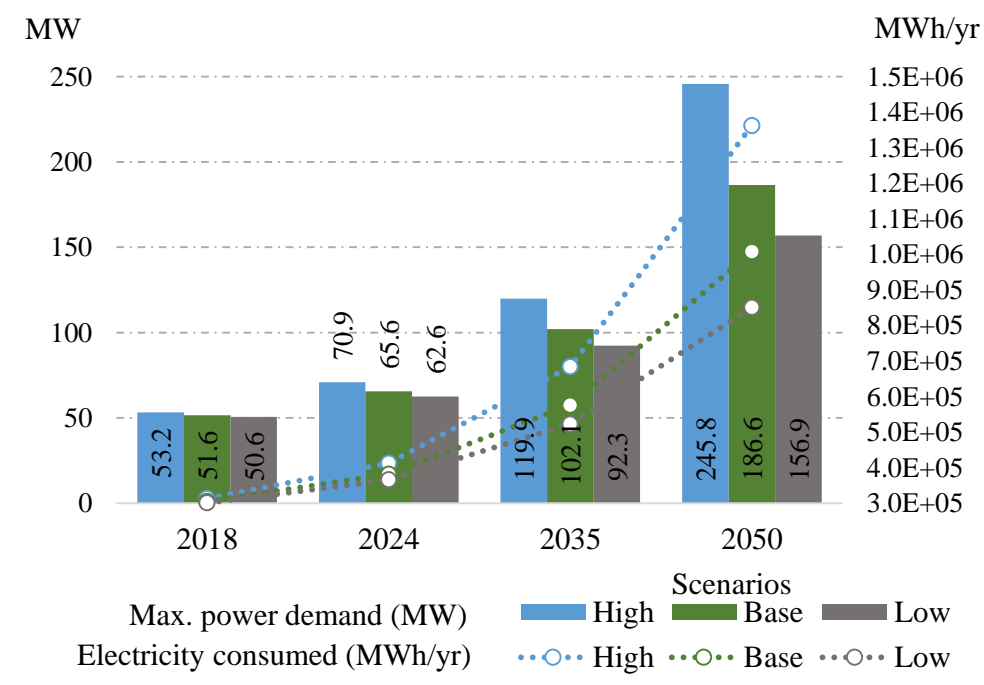

Figure 3: Maximum power demanded and electricity consumed for each year and scenario analyzed for Cozumel Island [4].

shows the arrangement in the RES combination in 5 Hectare (Ha) of land surface, for each 2 MW Wind turbine on-shore will be $333.33 \mathrm{~kW}$ of PV array. Meanwhile, Fig. 5 shows the 
topology and the renewable electric system of the grid used, including the current generation and main transformation system [4].

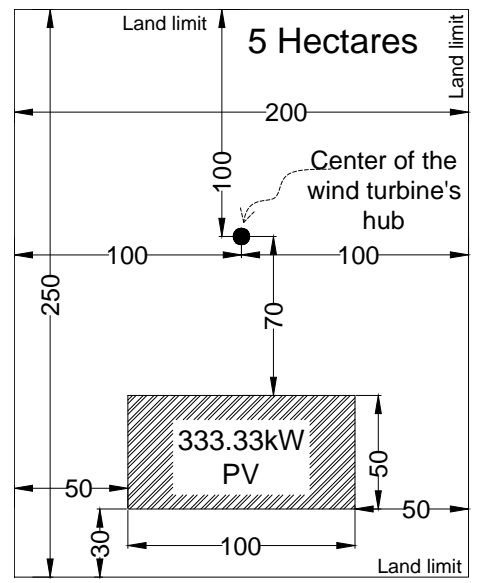

Figure 4: PV and wind turbine combination on a 5 Ha of the land size proposed (dimensioning in meters) [4.

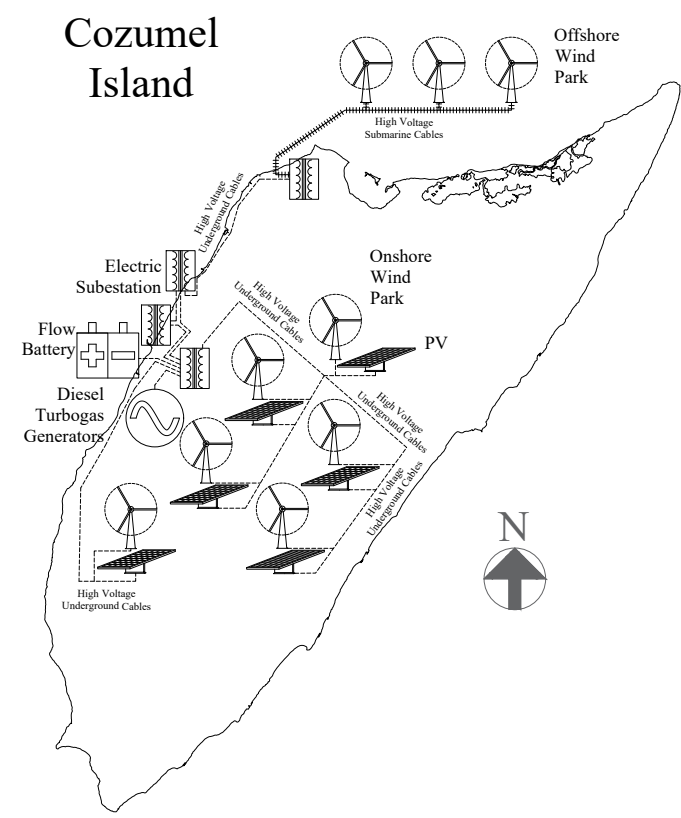

Figure 5: Topology and renewable electric system, including the current generation and main transformation system, proposed for Cozumel Island [4].

The sensitivity analysis is included on the basis of the use of two-dimensional linear interpolation through a probabilistic logic strategy using the complete enumeration method. Through this process, the software HOMER ${ }^{\complement}$ simulation model [44] determines the optimal values of variables that the system designer controls, such as the mix of components that make up the system and the size or quantity of each variable. Other studies that have used this software or a similar one to integrate the renewable electricity generation on the electric grids were reviewed [6] [7] [32] [45] [46] [47] [48] [49]. The optimum system or the best 
system configuration is the one that satisfies the specified constraints at the lowest total NPC. This simulation model uses the multiyear analysis. This model is based on a time-domain simulation run at the energy-flow level with discrete time-steps of 1 hour. It determines the NPV for a chosen configuration over a specified project lifetime [50]. More information about the model formulation is available at [39] [40]. Table 3 shows the technology used in the simulations that have done, including the four different battery technology: Ion-Lithium, Lead-Acid, Vanadium Redox Flow and Zinc-Bromine Redox Flow.

Table 3: Technologies to consider in the simulations including the sensitivity constraints and the four different battery types

\begin{tabular}{|c|c|c|c|c|c|c|c|c|c|c|c|c|c|c|}
\hline \multirow{2}{*}{$\begin{array}{c}\text { Battery } \\
\text { System type }\end{array}$} & \multirow{2}{*}{$\begin{array}{l}\text { PV } \\
\text { Array }\end{array}$} & \multirow{2}{*}{$\begin{array}{l}\text { SE11520 } \\
\text { 2MW On }\end{array}$} & \multirow{2}{*}{$\begin{array}{c}\text { Enercon E115 } \\
\text { 3MW Off }\end{array}$} & \multicolumn{3}{|c|}{$2018,2024,2035$ and 2050} & \multirow{2}{*}{$\begin{array}{l}\text { 2024, } 2035 \text { and } 2050 \\
\text { Unit5 }\end{array}$} & \multirow[b]{2}{*}{ Converter } & \multirow{2}{*}{$\begin{array}{l}\text { Inflation } \\
\text { Rate (\%) }\end{array}$} & \multirow{2}{*}{$\begin{array}{c}\text { Cost } \\
\text { Reduction } \\
\end{array}$} & \multirow{2}{*}{$\begin{array}{l}\text { Efficiency } \\
\text { Improved }\end{array}$} & \multicolumn{3}{|c|}{ Scenarios } \\
\hline & & & & Unit1 & Unit2 & Unit4 & & & & & & Low & Base & High \\
\hline Ion-Lithium & $\sqrt{ }$ & $\sqrt{ }$ & $\sqrt{ }$ & $\sqrt{ }$ & $\sqrt{ }$ & $\sqrt{ }$ & $\sqrt{ }$ & $\sqrt{ }$ & 2.0 & & & $\sqrt{ }$ & $\sqrt{ }$ & $\sqrt{ }$ \\
\hline Ion-Lithium & $\sqrt{ }$ & $\sqrt{ }$ & $\sqrt{ }$ & $\sqrt{ }$ & $\sqrt{ }$ & $\sqrt{ }$ & $\sqrt{ }$ & $\sqrt{ }$ & 2.5 & $\sqrt{ }$ & $\sqrt{ }$ & $\sqrt{ }$ & $\sqrt{ }$ & $\sqrt{ }$ \\
\hline Lead-Acid & $\sqrt{ }$ & $\sqrt{ }$ & $\sqrt{ }$ & $\sqrt{ }$ & $\sqrt{ }$ & $\sqrt{ }$ & $\sqrt{ }$ & $\sqrt{ }$ & 2.0 & & & $\sqrt{ }$ & $\sqrt{ }$ & $\sqrt{ }$ \\
\hline Lead-Acid & $\sqrt{ }$ & $\sqrt{ }$ & $\sqrt{ }$ & $\sqrt{ }$ & $\sqrt{ }$ & $\sqrt{ }$ & $\sqrt{ }$ & $\sqrt{ }$ & 2.5 & $\sqrt{ }$ & $\sqrt{ }$ & $\sqrt{ }$ & $\sqrt{ }$ & $\sqrt{ }$ \\
\hline $\begin{array}{l}\text { Vanadium } \\
\text { Redox Flow }\end{array}$ & $\sqrt{ }$ & $\sqrt{ }$ & $\sqrt{ }$ & $\sqrt{ }$ & $\sqrt{ }$ & $\sqrt{ }$ & $\sqrt{ }$ & $\sqrt{ }$ & 2.0 & & & $\sqrt{ }$ & $\sqrt{ }$ & $\sqrt{ }$ \\
\hline $\begin{array}{c}\text { Vanadium } \\
\text { Redox Flow }\end{array}$ & $\sqrt{ }$ & $\sqrt{ }$ & $\sqrt{ }$ & $\sqrt{ }$ & $\sqrt{ }$ & $\sqrt{ }$ & $\sqrt{ }$ & $\sqrt{ }$ & 2.5 & $\sqrt{ }$ & $\sqrt{ }$ & $\sqrt{ }$ & $\sqrt{ }$ & $\sqrt{ }$ \\
\hline $\begin{array}{l}\text { Zinc-Bromine } \\
\text { Redox Flow }\end{array}$ & $\sqrt{ }$ & $\sqrt{ }$ & $\sqrt{ }$ & $\sqrt{ }$ & $\sqrt{ }$ & $\sqrt{ }$ & $\sqrt{ }$ & $\sqrt{ }$ & 2.0 & & & $\sqrt{ }$ & $\sqrt{ }$ & $\sqrt{ }$ \\
\hline $\begin{array}{l}\text { Zinc-Bromine } \\
\text { Redox Flow }\end{array}$ & $\sqrt{ }$ & $\sqrt{ }$ & $\sqrt{ }$ & $\sqrt{ }$ & $\checkmark$ & $\sqrt{ }$ & $\sqrt{ }$ & $\sqrt{ }$ & 2.5 & $\sqrt{ }$ & $\sqrt{ }$ & $\sqrt{ }$ & $\sqrt{ }$ & $\sqrt{ }$ \\
\hline
\end{tabular}

\subsection{Hybrid system analysis and results}

Results from the renewable energy system in combination with four different battery technologies show the number of batteries changes according to the type used. This is to maintain the backup time of $0.5 \mathrm{~h}$ and a REF penetration of $41.1 \%$ in the year 2018 and in the Base Scenario. These results came from 121 number of combinations of the hybrid system with the four different battery technologies, as shown in Fig. 6. In this graph, the red line is the backup time and the grey line is the batt-ratio. The green columns represent the REF penetration on the grid. In systems from 1 to 7 the battery bank is not considered. The four different batteries type are presented, as can be seen in this figure, but only the Lead- Acid, the Vanadium, and the Zinc-Bromine battery need a batt-ratio of 0.2 in order to have $0.5 \mathrm{~h}$ of backup time at least. For the Ion-Lithium battery, requires a batt-ratio of 0.3 for $\mathrm{a} \geq 0.5 \mathrm{~h}$ of backup time.

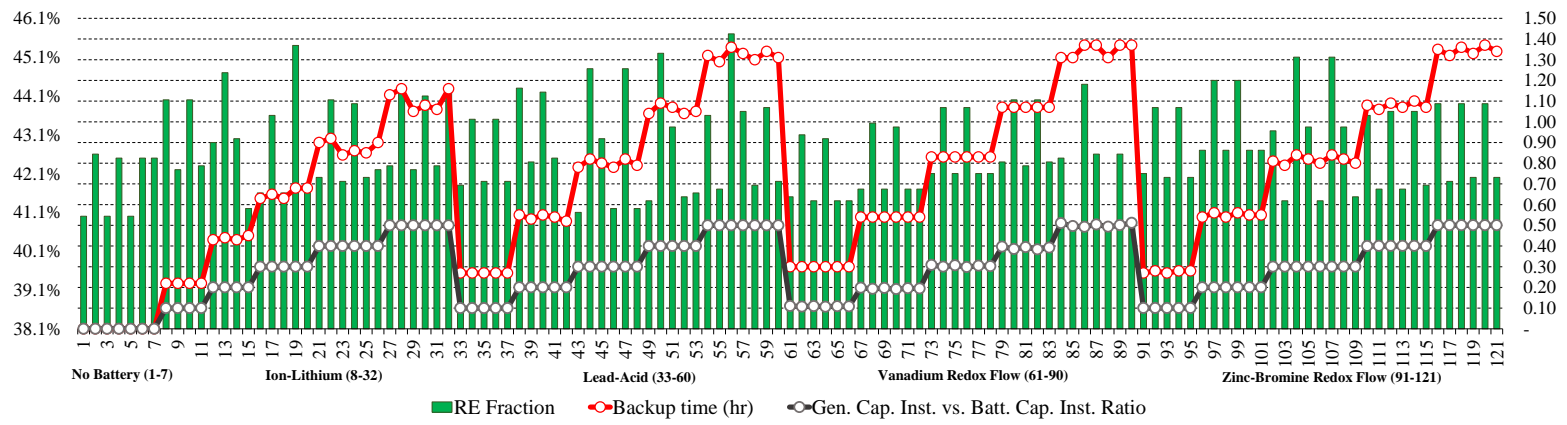

Figure 6: Results for the 121 hybrid power system in combination with the four batteries type in the Base Scenario by 2018 for Cozumel Island.

The selected systems, in which all the constrains are fulfilled in REF and backup time, are shown in Fig. 7 for each battery type in the same year and scenario. The green line 
is the backup time, the black line is the REF factor, the brown line is batt-ratio and the columns are the sum of the hybrid power generation capacity of its components, including the converter capacity. As in this graph appears all the systems that fulfil the constrains of all battery technologies, the economic analysis will determine the resultant system for each battery category. In Fig. 8 the hybrid system selected for each battery category is

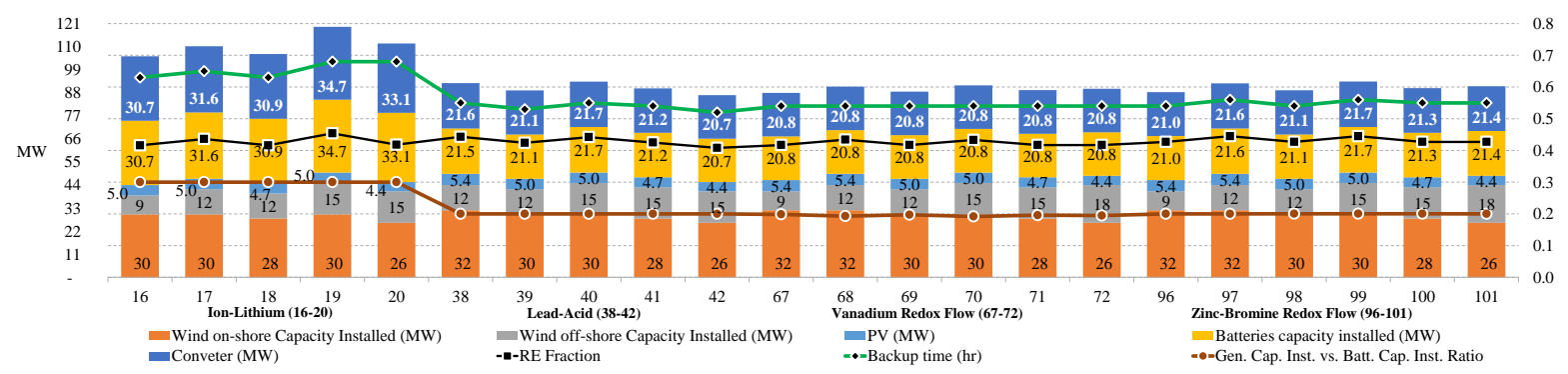

Figure 7: Results for the hybrid power system in combination with the four batteries type that fulfil the constrains in the Base Scenario by 2018 for Cozumel Island.

shown. In this graph, the same description and colours that in Fig. 7 is used to describe the results in each battery category. Fig. 9 and Fig. 10 shown the economic results by 2018 in the Base Scenario, which validate the hybrid systems selected in the last two figures. First, Fig. 9 shows that the system with the Zinc-Bromine battery bank has the highest IRR, the minimum ICC and the minimum time is taken for the Retention Guarantee Fund (RGF) to be equal to ICC. These economic results do not lessen the minimum IRR of $13.5 \%$ [51] [43. Secondly, Fig. 10 shows the maximum NPV, the minimum LCOE, and the minimum NPC. The economic comparative is elaborated with an inflation rate of $2.0 \%$, which does not include the cost reductions and the efficiency increase through the years as the worst case. The best case is made with a $2.5 \%$ of inflation rate, including the cost reductions and the efficiency increase through the years. The system selected by its best economic results is the system that includes the Zinc-Bromine battery bank. Fig. 11 shows the economic results by 2050 in the Base Scenario. The 2\% indicator means that the cost reductions and the inflation rate are not been applied. Therefore, the $2.5 \%$ indicator means that the cost reductions and the inflation rate are been applied.

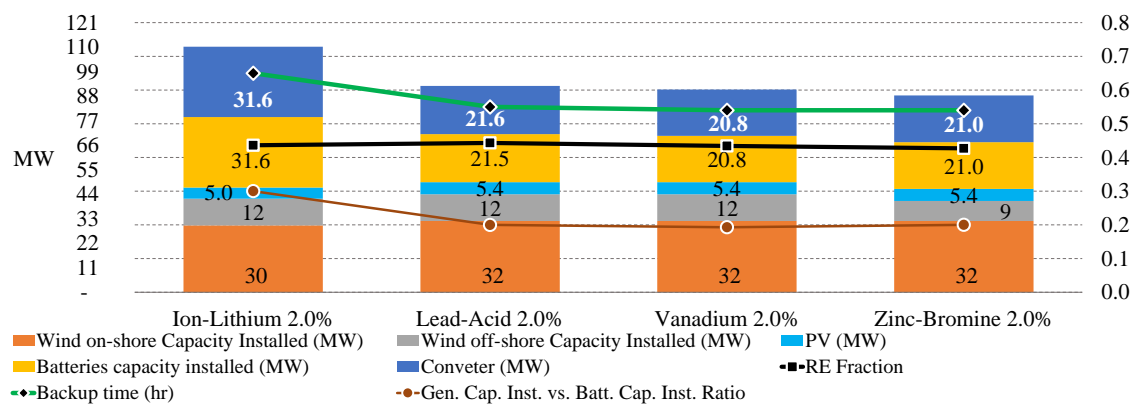

Figure 8: Results for the hybrid power system selected in combination with the four batteries type that fulfil the constrains in the Base Scenario by 2018 for Cozumel Island. 


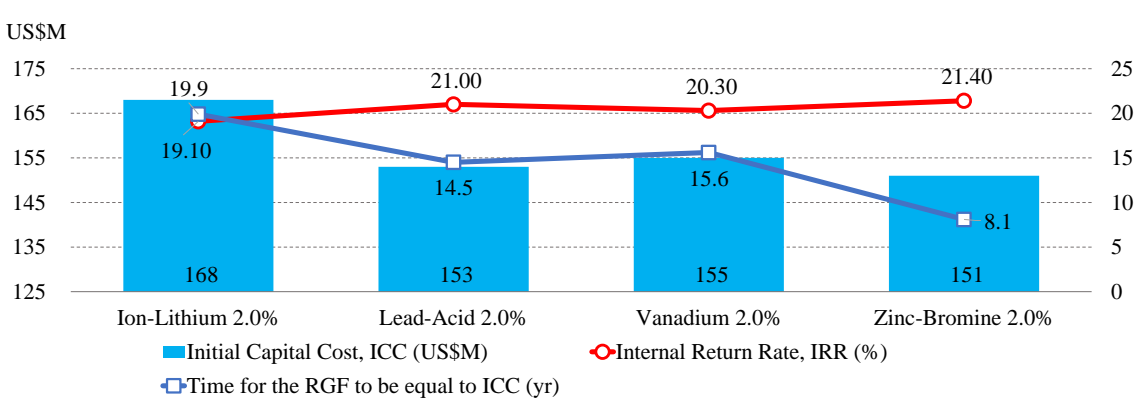

Figure 9: Economic results for the hybrid power system selected with the batteries type in the Base Scenario by 2018 for Cozumel Island.

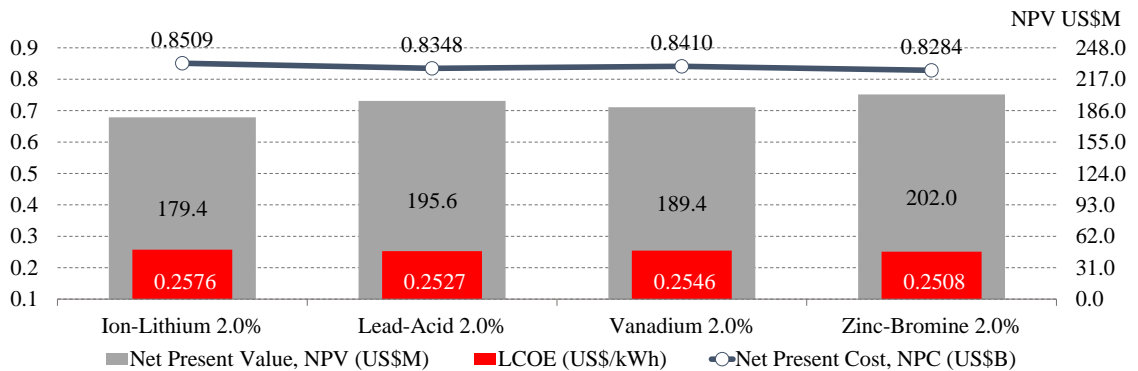

(a) Economic results with $2.0 \%$ of inflation rate

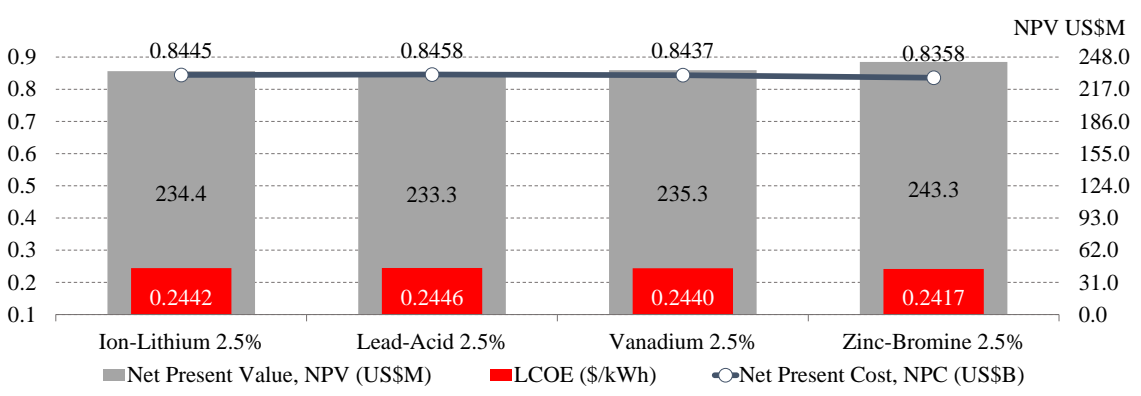

(b) Economic results with $2.5 \%$ of inflation rate

Figure 10: Economic results without (a) and with (b) the sensitivity variables for the hybrid power system selected with the batteries type in the Base Scenario by 2018 for Cozumel Island.

Fig. 12 shows the results in the ICC applying the cost reductions and the inflation rate increase. These results are for the Base Scenario by 2018 (a) and by 2050 (b). In this figure, the reduction in the cost of the equipment it will be applied until 2050.

\section{A reliable assessment of the static and dynamic grid safe response in a fossil fuel and in a $100 \%$ renewable electric system}

In the previous results, the $100 \%$ of the renewable generation supplying the electric load was given during 188 hours by 2018. By 2024 this 100\% of renewable energy supplying the electric load was given during 209 hours. By 2035 this 100\% of renewable energy supplying the electric load was given during 509 hours. By 2050 this $100 \%$ of renewable energy supplying the electric load was given during 1,258 hours. The following steady-state analysis and the 


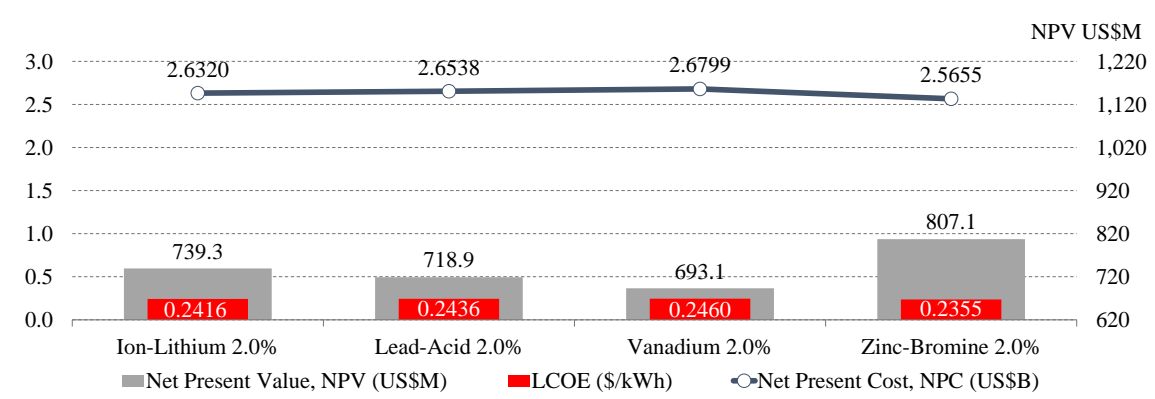

(a) Economic results with $2.0 \%$ of inflation rate

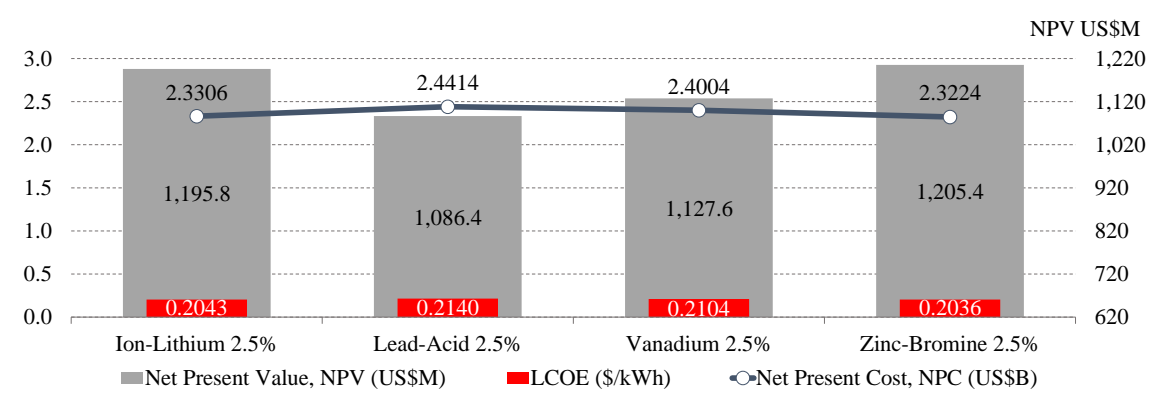

(b) Economic results with $2.5 \%$ of inflation rate

Figure 11: Economic results without (a) and with (b) the sensitivity variables for the hybrid power system selected with the batteries type in the Base Scenario by 2050 for Cozumel Island.

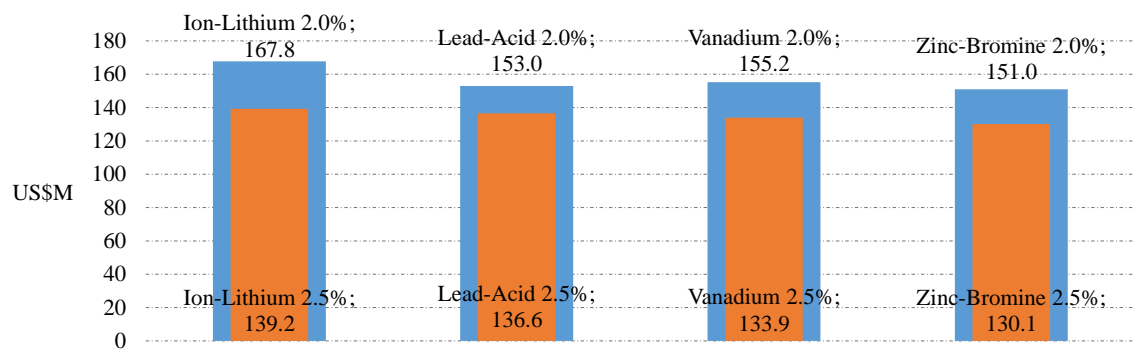

(a) ICC results by 2018 with $2 \%$ and $2.5 \%$ indicators applied.

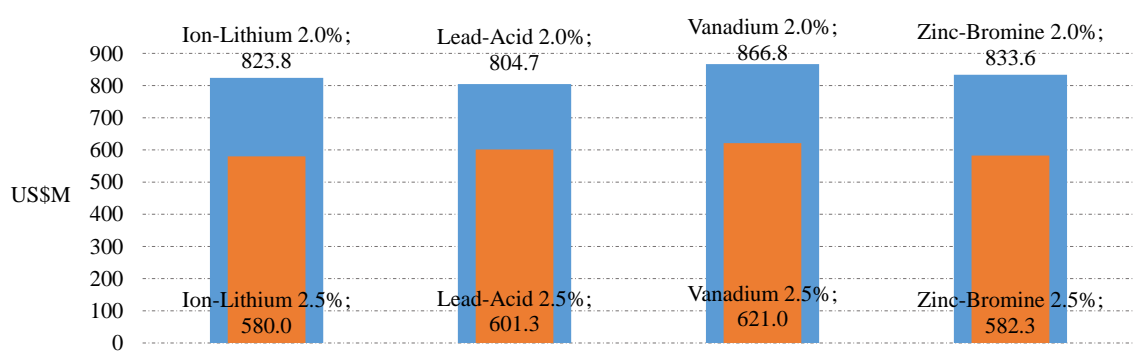

(b) ICC results by 2050 with $2 \%$ and $2.5 \%$ indicators applied.

Figure 12: ICC results with and without cost reductions, and inflation rate increasing for the hybrid power system selected with the batteries type in the Base Scenario by 2018 (a) and by 2050 (b) for Cozumel Island.

dynamic analysis are done under a 100\% of renewable energy supplying the electric load. In the following sections, the steady-state analysis is done for two options: 1) An electric grid with only fossil fuel power generation in the three scenarios (Low, Base 
and High) and through the key years selected (2018, 2024, 2035, 2050), and; 2) An electric grid with a hybrid power generation in the same scenarios and years.

\subsection{Steady-state analysis and results}

In a non-faulted or steady-state (free of short-circuit) conditions, the load flow calculations to analyze the power system are used. In this steady-state, all the variables and parameters on the grid are assumed as constants during the period of time analyzed. This reflects the system response in a specific time with the specific variables and parameters given [35]. To do this, the Newton Rapshon method can be used in a numerical iterative way. The basic formulas for the derivative power flow equations based on the admittance of the network can solve by means of this method [52] [53]. First at all, with the grid data in 2018 the power flow analysis is carried out, and once the grid is stable, reliable, and with a safe response, the simulations analysis for the year of 2024 will be done. If the grid does not respond within the allowed parameters, then the reinforcements or modifications will be done until the system response will be stable. This new grid will be the initial one to run the 2035 steady-state analysis and so on until 2050. For the Base Scenario and in the year 2018 the grid has been modified and reinforced after the hourly power flow analysis. The voltage results in the busbars are shown in Table 4. The loading results from the hourly power flow analysis for the same scenario and year are shown in Table 5. In these results tables, for the fossil fuel generation option and for the $100 \%$ renewable generation option, the results are compared. With the same power demand to supply, it can see that the voltages values in the busbars are improved when the distributed renewable generation is placed and integrated (see Fig. 5 for the renewable technology sites), which is shown in Table 4 and Table 5 . These results in voltage and loading are within the MGC parameters for a continuous system operation [38].

The grid code is the interconnection rules and controls for the RETs or any generation sources at the moment they are integrated into the electric system, keeping the reliability and stability of the electrical grid. To make this possible, this grid code has the minimum or maximum control and protection parameters. The grid code depends on the country in which the RETs are going to be interconnected. For instance, Fig. 13 shows the different system response boundaries in case of a fault in the electric system. This failure produces a voltage dips in the system and is indicated for Mexico, Ecuador, UK, and Continental Europe. These graphs are the limits of the system response.

In the power flow, the hourly power demand for each load of the Cozumel Island are analyzed through a DIgSILENT Programming Language (DPL) command script function [35]. This function allows the hourly power system simulations during the year and its power flow response (Quasy-dynamic simulations). As January 17th at 19:00 h by 2018 is the time that the $100 \%$ of the electric load is supplied by the renewable generation, it has chosen \pm 1 day in the operation analysis results signals to show.

Fig. 14 shows the fossil fuel units operation comparing a fossil fuel generation grid (continuous lines) vs. renewable energy generation grid (dotted lines). As it can be seen, the present of the intermittent and variable energy production of the renewable technologies on the grid modify substantially the fossil fuel operation of the generation units in the virtual date from January 16th at 00:00 h to January 19th at 00:00 h by 2018. In case of a fossil fuel generation grid (continuous lines), the fossil fuel unit operation follow the load profile 


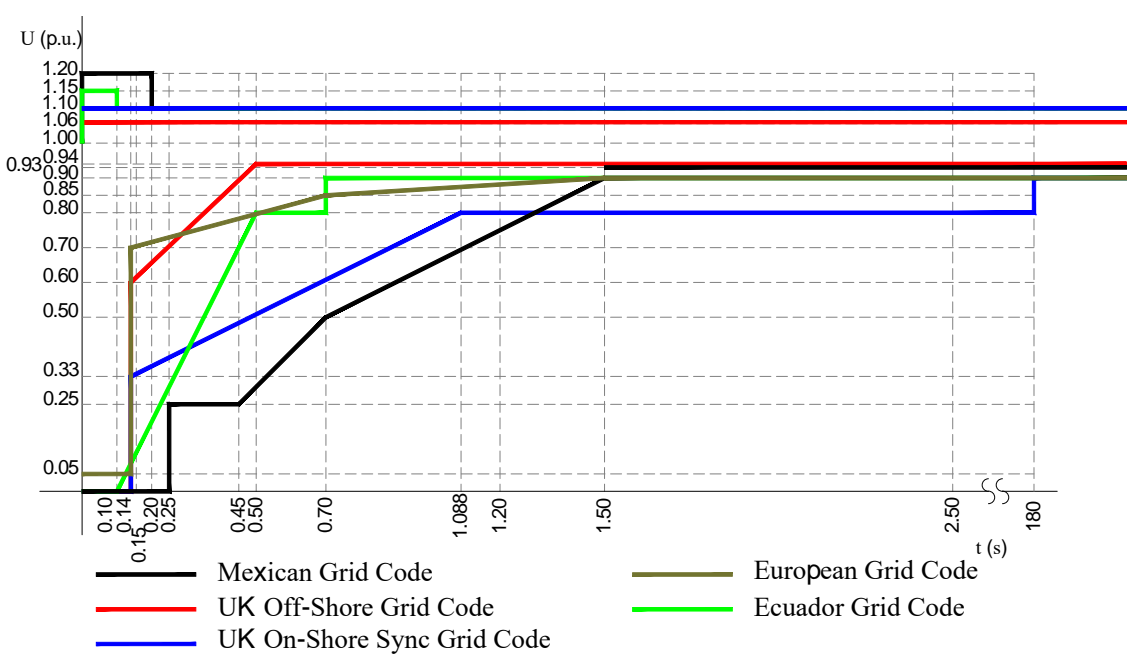

Figure 13: Different system response boundaries in the grid codes for Mexico, Ecuador, UK and Continental Europe in a presence of a fault that produces a voltage dips in the system.

Table 4: Voltage results of the hourly power flow analysis in a fossil fuel generation grid (upper part), and in a 100\% renewable generation grid (lower part) in the Base Scenario by 2018 in Cozumel, Island.

Fossil Fuel Generation Grid

\begin{tabular}{|c|c|c|c|c|}
\hline $\begin{array}{l}\text { Branch, } \\
\text { Substation } \\
\text { or Site }\end{array}$ & $\begin{array}{l}\text { Voltage } \\
\text { Max. } \\
\text { (p.u.) }\end{array}$ & $\begin{array}{c}\text { Time Point } \\
\text { Max }\end{array}$ & $\begin{array}{c}\text { Voltage } \\
\text { Min. } \\
\text { (p.u.) }\end{array}$ & $\begin{array}{c}\text { Time Point } \\
\text { Min }\end{array}$ \\
\hline Cedral & 0.983 & 2018.01.13 04:00:00 & 0.931 & 2018.09.02 22:00:00 \\
\hline Chankanaab $34.5 \mathrm{kV}$ & 1.002 & 2018.01.03 04:00:00 & 0.993 & 2018.09.17 22:00:00 \\
\hline Chankanaab U1 $13.8 \mathrm{kV}$ & 1.000 & 2018.03.01 10:00:00 & 1.000 & 2018.04.05 05:00:00 \\
\hline Chankanaab U2 $13.8 \mathrm{kV}$ & 1.000 & 2018.03.0110:00:00 & 1.000 & 2018.04.03 05:00:00 \\
\hline Chankanaab U4 $13.8 \mathrm{kV}$ & 1.000 & 2018.01.01 00:00:00 & 1.000 & 2018.01.01 00:00:00 \\
\hline Mega $13.8 \mathrm{kV}$ & 0.994 & 2018.01.05 04:00:00 & 0.963 & 2018.09.24 22:00:00 \\
\hline Mega $34.5 \mathrm{kV}$ & 1.001 & 2018.01.03 04:00:00 & 0.988 & 2018.09.17 22:00:00 \\
\hline Office $13.8 \mathrm{kV}$ & 0.995 & 2018.01.26 04:00:00 & 0.964 & 2018.09.14 22:00:00 \\
\hline Office $34.5 \mathrm{kV}$ & 1.002 & 2018.01.03 04:00:00 & 0.989 & 2018.09.17 22:00:00 \\
\hline \multicolumn{5}{|c|}{$100 \%$ Renewable Generation Grid } \\
\hline Cedral & 1.013 & 2018.01.11 04:00:00 & 0.946 & 2018.09.04 22:00:00 \\
\hline Chankanaab $34.5 \mathrm{kV}$ & 1.002 & 2018.02.06 03:00:00 & 0.995 & 2018.09.10 22:00:00 \\
\hline Chankanaab U1 $13.8 \mathrm{kV}$ & 1.000 & 2018.01.31 01:00:00 & 1.000 & 2018.04 .09 12:00:00 \\
\hline Chankanaab U2 $13.8 \mathrm{kV}$ & 1.000 & 2018.01.31 01:00:00 & 1.000 & 2018.07.07 14:00:00 \\
\hline Chankanaab U4 $13.8 \mathrm{kV}$ & 1.000 & 2018.01.01 00:00:00 & 1.000 & 2018.01.01 00:00:00 \\
\hline Mega $13.8 \mathrm{kV}$ & 0.995 & 2018.01.15 04:00:00 & 0.967 & 2018.09.2122:00:00 \\
\hline Mega $34.5 \mathrm{kV}$ & 1.002 & 2018.01.15 04:00:00 & 0.992 & 2018.09.21 22:00:00 \\
\hline Office $13.8 \mathrm{kV}$ & 0.996 & 2018.01.15 04:00:00 & 0.967 & 2018.09.10 22:00:00 \\
\hline Office $34.5 \mathrm{kV}$ & 1.003 & 2018.01.15 04:00:00 & 0.992 & 2018.09.10 22:00:00 \\
\hline
\end{tabular}

in the grid. Meanwhile, in the renewable energy generation grid (dotted lines), the fossil fuel unit operation does not follow the load profile in the grid. The $100 \%$ of the electric 
Table 5: Loading results of the hourly power flow analysis in a fossil fuel generation grid (upper part), and in a 100\% renewable generation grid (lower part) in the Base Scenario by 2018 in Cozumel, Island.

Fossil Fuel Generation Grid

\begin{tabular}{|c|c|c|c|c|}
\hline $\begin{array}{l}\text { Branch, } \\
\text { Substation } \\
\text { or Site }\end{array}$ & $\begin{array}{c}\text { Max. } \\
\text { Loading } \\
{[\%]}\end{array}$ & $\begin{array}{c}\text { Time Point } \\
\text { Max }\end{array}$ & $\begin{array}{c}\text { Min. } \\
\text { Loading } \\
{[\%]}\end{array}$ & $\begin{array}{c}\text { Time Point } \\
\text { Min }\end{array}$ \\
\hline Cedral- Chankanaab & 31.4 & 2018.09.26 22:00:00 & 8.3 & 2018.01.18 04:00:00 \\
\hline Chankanaab- Mega & 18.7 & 2018.09.10 22:00:00 & 4.9 & 2018.01.28 04:00:00 \\
\hline Office- Chankanaab & 28.7 & 2018.09.16 22:00:00 & 8.1 & 2018.01.08 04:00:00 \\
\hline Office-Mega & 6.8 & 2018.09.27 22:00:00 & 3.1 & 2018.01.27 04:00:00 \\
\hline Tie Transfer U1-U2 & 0.0 & 2018.03.20 10:00:00 & 0.0 & 2018.06.28 11:00:00 \\
\hline Tie Transfer U2-U4 & 0.0 & 2018.01.01 00:00:00 & 0.0 & 2018.01.01 02:00:00 \\
\hline Tranformer U1 & 25.3 & 2018.09.19 22:00:00 & 6.3 & 2018.01.31 04:00:00 \\
\hline Tranformer U2 & 11.3 & 2018.09.14 22:00:00 & 2.7 & 2018.03.24 03:00:00 \\
\hline Tranformer U4 & 64.7 & 2018.09.06 22:00:00 & 17.9 & 2018.01.23 04:00:00 \\
\hline Transf. Mega & 48.2 & 2018.09.10 22:00:00 & 13.2 & 2018.01.05 04:00:00 \\
\hline Transf. Office & 48.7 & 2018.09.16 22:00:00 & 13.4 & 2018.01.2604:00:00 \\
\hline Unit 1 (U1) & 82.7 & 2018.09.11 22:00:00 & 19.1 & 2018.01.08 04:00:00 \\
\hline Unit 2 (U2) & 71.8 & 2018.09.14 22:00:00 & 17.6 & 2018.01.12 04:00:00 \\
\hline Unit 4 (U4) & 67.263 & 2018.09.06 22:00:00 & 18.236 & 2018.01.06 04:00:00 \\
\hline \multicolumn{5}{|c|}{ Hybrid Generation Grid } \\
\hline Cedral- Chankanaab & 27.7 & 2018.09.04 22:00:00 & 2.84 & 2018.01.31 04:00:00 \\
\hline Chankanaab- Mega & 17.6 & 2018.09.04 22:00:00 & 0.94 & 2018.10.05 05:00:00 \\
\hline Office- Chankanaab & 27.8 & 2018.09.04 22:00:00 & 1.22 & 2018.11.18 02:00:00 \\
\hline Office-Mega & 9.9 & 2018.01.11 04:00:00 & 2.00 & 2018.01.02 04:00:00 \\
\hline Tie Transfer U1- U2 & 0.0 & 2018.01.31 01:00:00 & 0.02 & 2018.07.18 10:00:00 \\
\hline Tie Transfer U2- U4 & 0.0 & 2018.01.01 00:00:00 & 0.02 & 2018.01.01 00:00:00 \\
\hline Tranformer U1 & 36.7 & 2018.04.26 22:00:00 & 0.43 & 2018.12.19 03:00:00 \\
\hline Tranformer U2 & 23.7 & 2018.03.15 21:00:00 & 0.34 & 2018.01.03 10:00:00 \\
\hline Tranformer U4 & 86.2 & 2018.01.11 04:00:00 & 0.35 & 2018.04.16 01:00:00 \\
\hline Transf. Mega & 48.0 & 2018.09.21 22:00:00 & 13.21 & 2018.01.15 04:00:00 \\
\hline Transf. Office & 48.6 & 2018.09.10 22:00:00 & 13.36 & 2018.01.24 04:00:00 \\
\hline Unit 1 (U1) & 71.5 & 2018.09.04 22:00:00 & 4.04 & 2018.02.06 03:00:00 \\
\hline Unit 2 (U2) & 67.4 & 2018.09.04 22:00:00 & 4.93 & 2018.01.14 04:00:00 \\
\hline Unit 4 (U4) & 65.6 & 2018.09.04 22:00:00 & 2.59 & 2018.01.17 03:00:00 \\
\hline
\end{tabular}

load is supplied by the renewable electricity during some hours of the day (Fig. 14 January 17th-18th).

In Fig. 15 the renewable electricity production by PV and Wind (On-Shore and OffShore) is shown. Table 4 shows the busbars voltage values improvement, due to the renewable energy integration on the Island's electric grid. Moreover, Fig. 16 shows this busbar voltages improvement, as can be seen in Fig. 16a, which indicates that the voltage values in a fossil fuel generation grid follow the load profile. Meanwhile, Fig. $16 \mathrm{~b}$ shows that the voltages values do not follow the load profile in the grid. Despite having voltage variations, these 


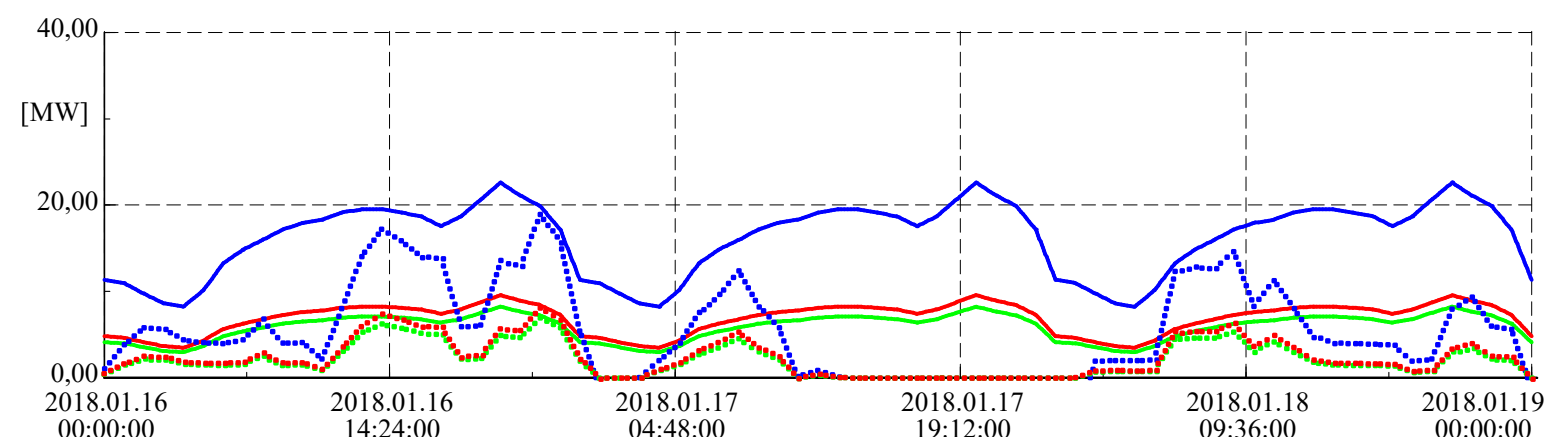

Active Power Units in a Fossil Fuel Generation Grid

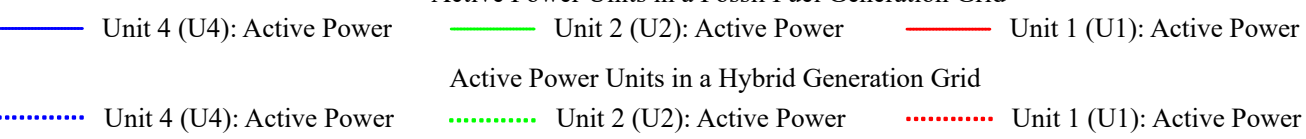

Figure 14: Active power in a fossil fuel generation grid (continuous lines), and active power in a $100 \%$ renewable generation grid (dotted lines) in the Base Scenario by 2018 for Cozumel Island. Virtual date: January 16 th to 19 th of 2018.

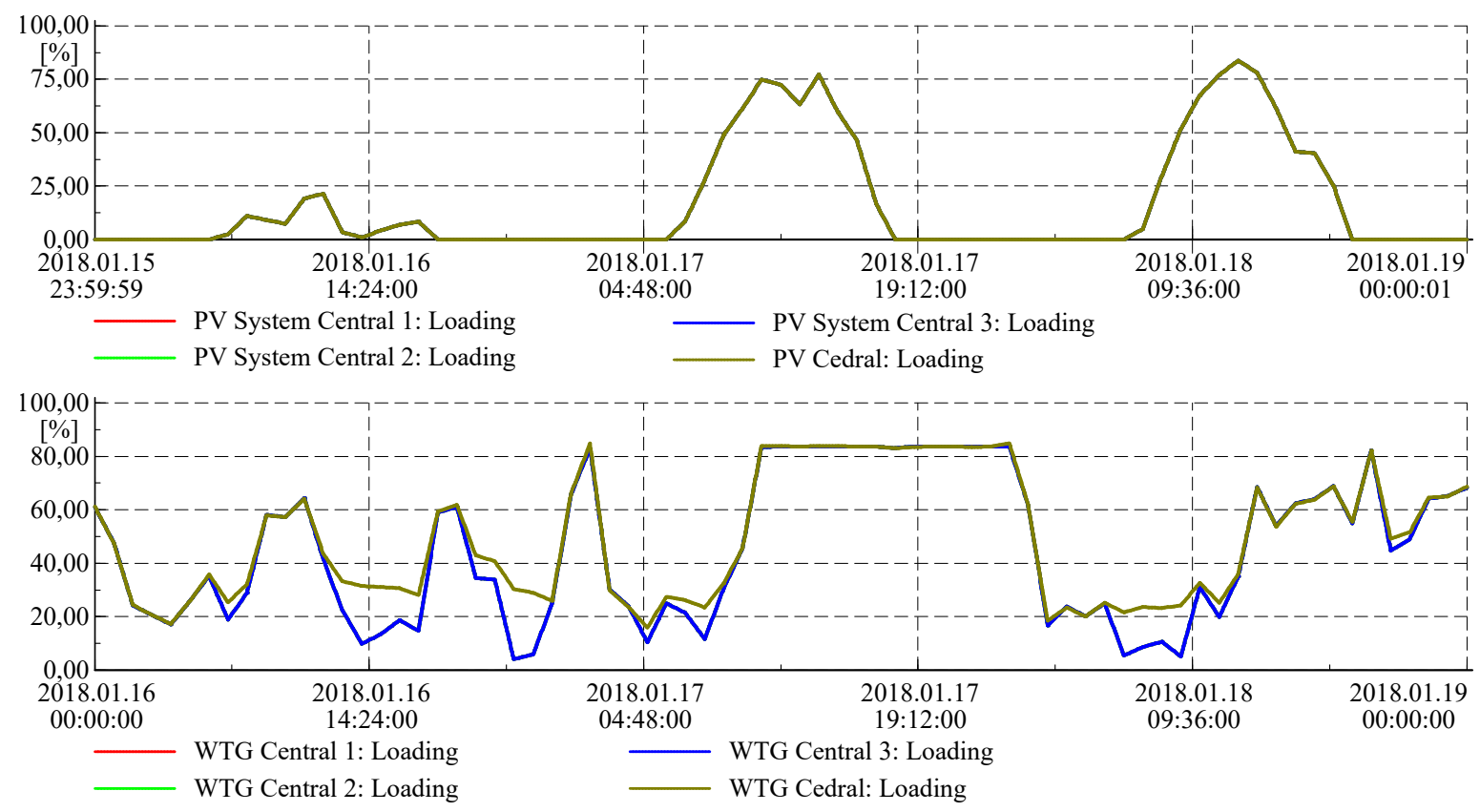

Figure 15: Renewable production loading in a $100 \%$ renewable generation grid. The upper figure indicates the photovoltaic production and the lower figure indicates the wind turbine generators (WTG) production. Base Scenario by 2018 for Cozumel Island. Virtual date: January 16th to 19th of 2018.

voltage values present an improvement.

\subsection{Dynamic analysis and results}

After small or large disturbance effects, the power systems must stay operating in a stable manner, and the system has to be able to return to the original steady-state without subsequent failures. Thereby, the stability analysis is made to ensure the voltage and frequency stability [36]. The transient stability is the power system ability of remain in synchrony in 


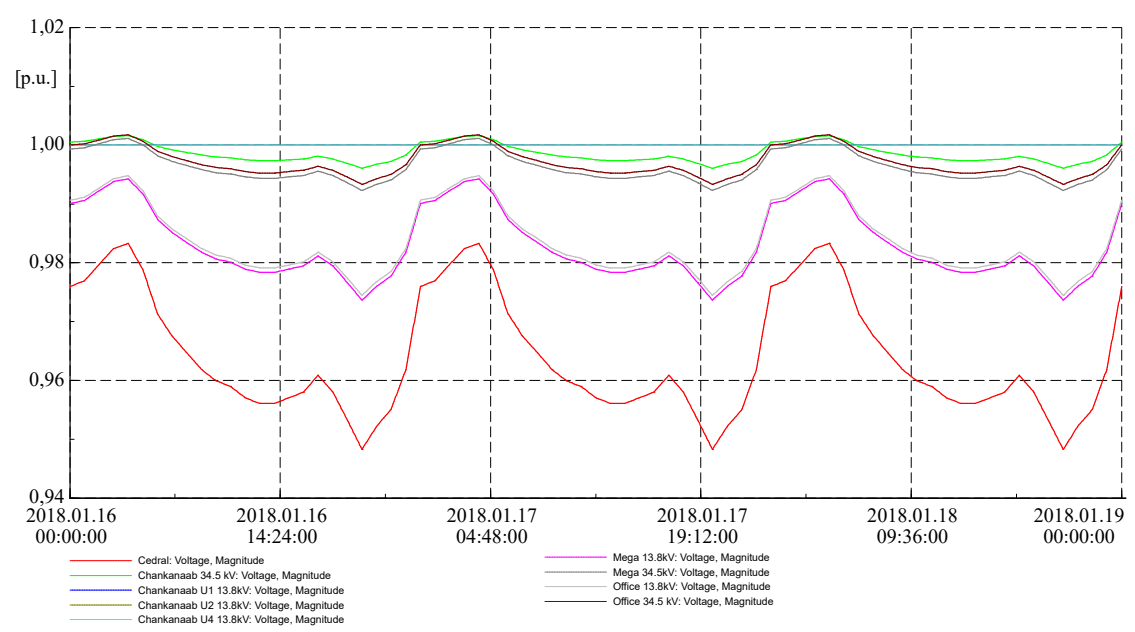

(a) Busbar voltages in a fossil fuel generation grid.

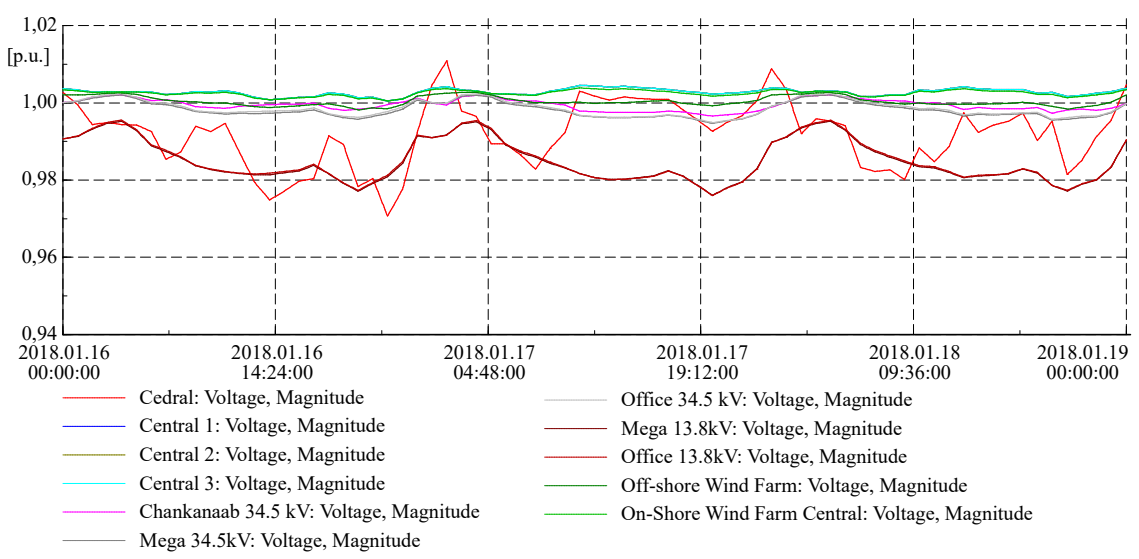

(b) Busbar voltages in a 100\% renewable generation grid.

Figure 16: Busbar voltages in a fossil fuel generation grid (a), and in a 100\% renewable generation grid (b) in the Base Scenario by 2018 for Cozumel Island. Virtual date: January 16th to 19th of 2018.

presence of small or large disturbances [54]. The numerical analysis techniques are used to solve these non-linear equations. Commonly the non-linear differential algebraic equations are used. Fig. 17 is a simple chart flow of what has been done in this stage, a dynamic state analysis to ensure that the grid response is within the MGC parameters and so returns to the previous steady state [55].

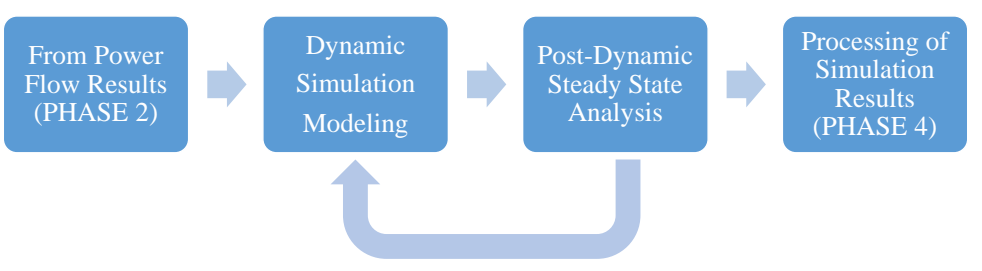

Figure 17: Phase 3 chart flow ([55] adapted)

The power system response when an electric load is lost and when Unit 2 is disconnected 
in a fossil fuel generation grid is shown in Fig. 18. The maximum frequency values for the Chankanaab busbar in $34.5 \mathrm{kV}$, the active power unit variation, and the maximum voltage in the units busbars are indicated in this figure. According to the MGC, the values for this frequency response must be 1.005 p.u. as the upper limit and 0.995 p.u. as the lower limit. Meanwhile, the values in voltage must be between 1.05 p.u. as the upper limit and 0.93 p.u. as the lower limit in medium tension $(\leq 34.5 \mathrm{kV})$ in a continuous operation (frequency and voltage limits are indicated with their upper and lower limits). These limit values are for an isolated electric system and the results are in the virtual date of September 11th at 22:00 $\mathrm{h}$ by 2018 , when the system reports a maximum power demand in a fossil fuel generation grid.

Unlike Fig. 18, which shows the fossil fuel generation grid operating when a load loss occurs, or when Unit 2 is disconnected, Fig. 19 shows the system response when the wind production is lost in a 100\% renewable energy generation grid. In Fig. 19 the maximum frequency values for the Chankanaab busbar in $34.5 \mathrm{kV}$, the active power units' variation, and the maximum voltage in the units busbars are indicated. The values for the frequency response and for the busbar voltage must be maintained within those previously indicated in a continuous operation. These limit values are for an isolated electric system, and the results are in the virtual date of January 17 th at 19:00 h by 2018, when the system reports a $100 \%$ of renewable production supplying the electric load. As can be seen in Fig. 19a, the frequency response signal goes beyond the isolated system lower limit during 0.89s. After this time the value returns to a continuous frequency value. Also, in Fig. 19c the voltage response signal goes beyond the isolated system upper limit during 0.80s. After this time the voltage value returns to a continuous voltage value. As MGC requires, the power system response is within the parameters for a continuous operation of the electric grid, for both options, isolated and interconnected system in a 100\% renewable energy generation grid. The resultant power flow chart for the Cozumel Island's electric grid when the renewable electricity generation supplying the $100 \%$ of the power demand is shown in Fig. 20. In this figure, the electric grid resultant values are indicated in the specific virtual date of January 17th at 19:00 h by 2018. The turbogas diesel machines are settled to supply the reactive power needed in the grid. 


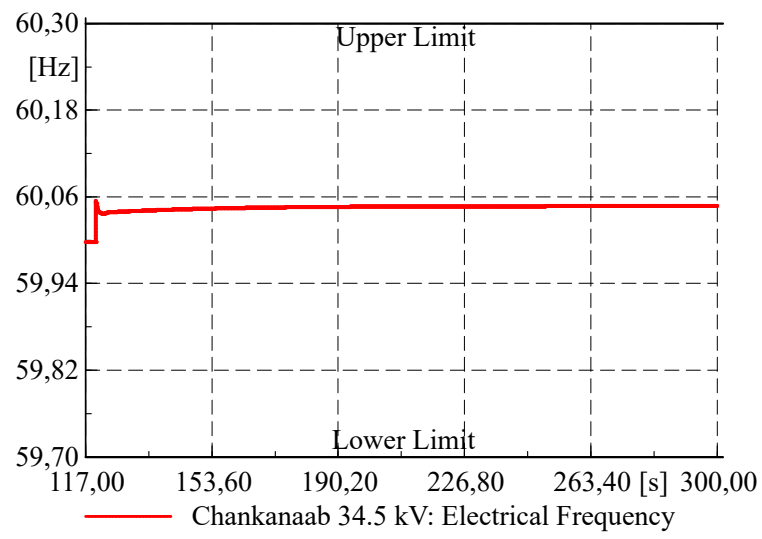

(a) Frequency response signal when an electric load is lost.

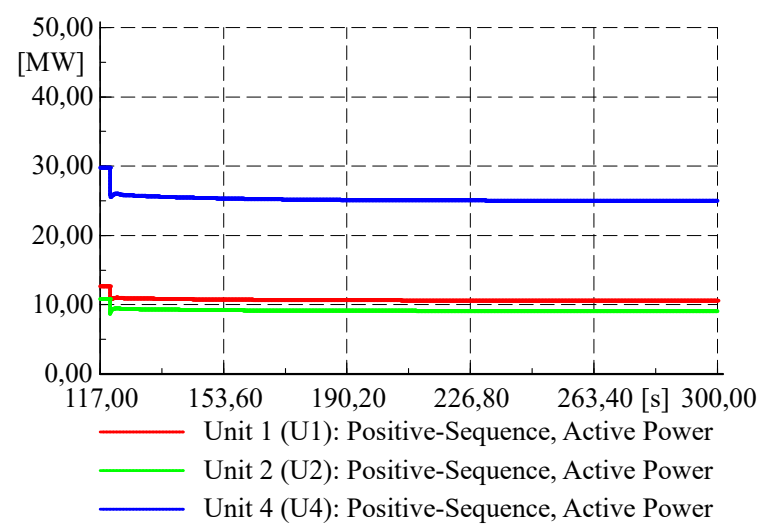

(c) Active power generation response signal when an electric load is lost.

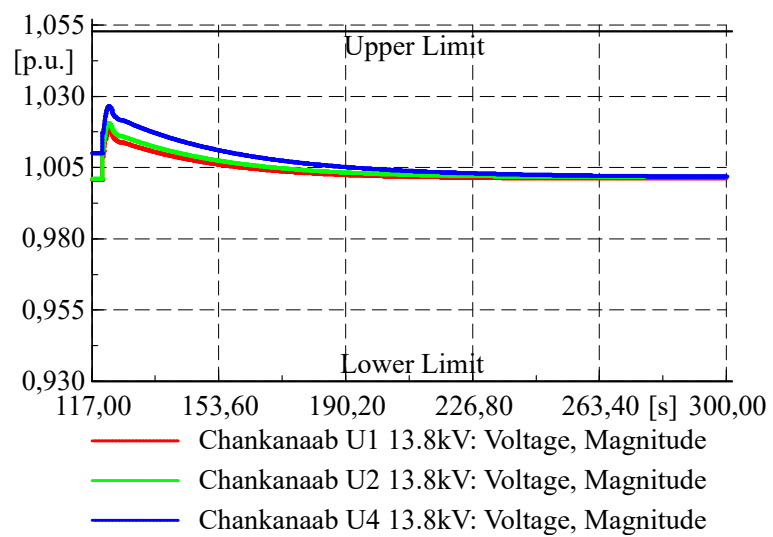

(e) Units busbar voltage response signal when an electric load is lost.

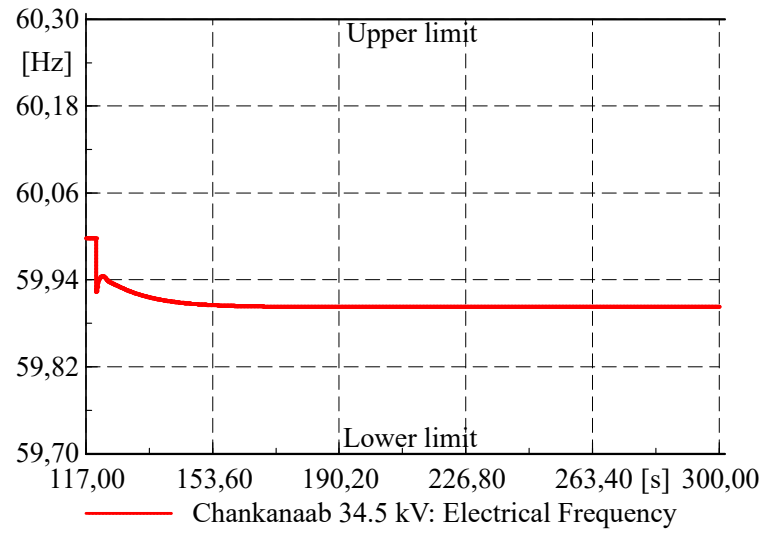

(b) Frequency response signal when Unit 2 is disconnected.

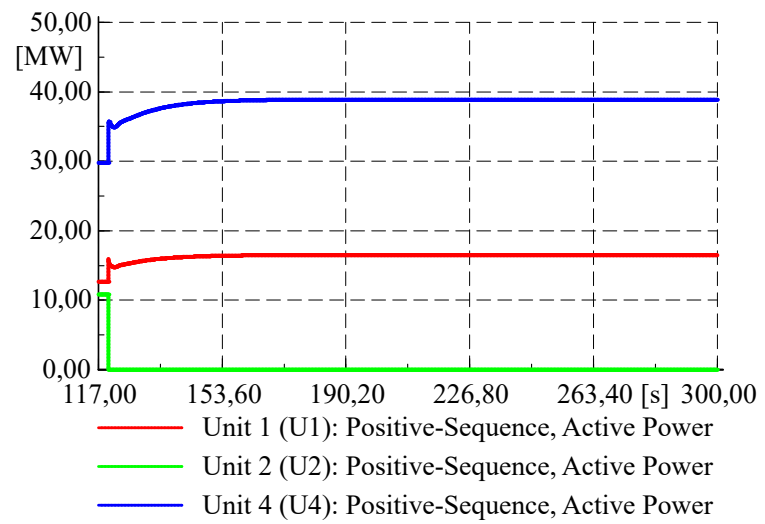

(d) Active power generation response signal when Unit 2 is disconnected.

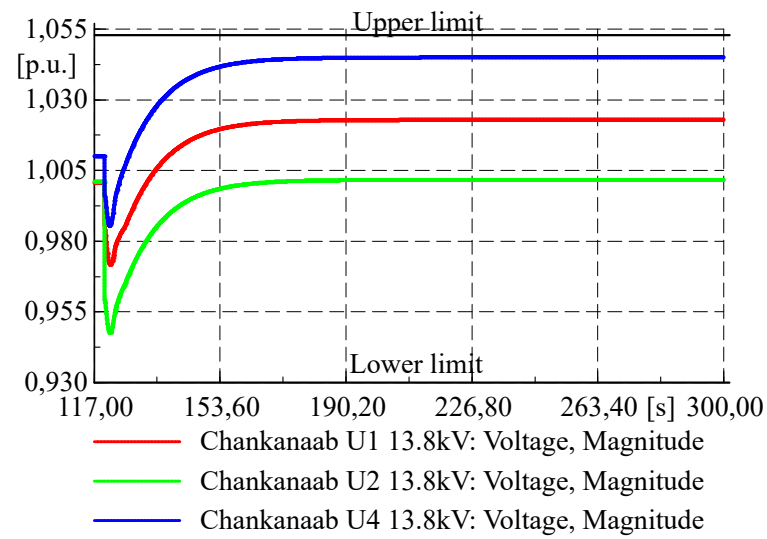

(f) Units busbar voltage response signal when Unit 2 is disconnected.

Figure 18: System response when an electric load is lost in the virtual date: September 11th at 22:00 h by 2018. (Figures 18a, 18c and 18e). System response when Unit 2 is disconnected in the virtual date: September 11th at 22:00 h by 2018. (Figures 18b, 18d and 18f). Running on the basis of a fossil fuel generation grid, in a Base Scenario for Cozumel Island. 


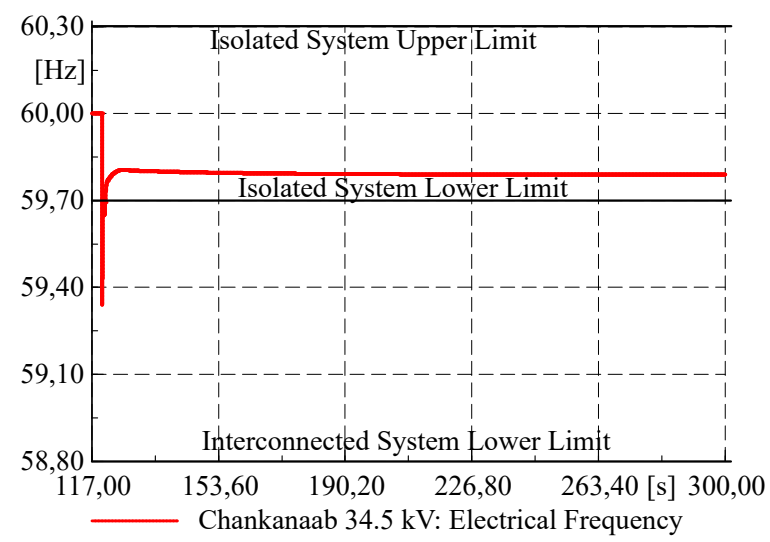

(a) Frequency response.

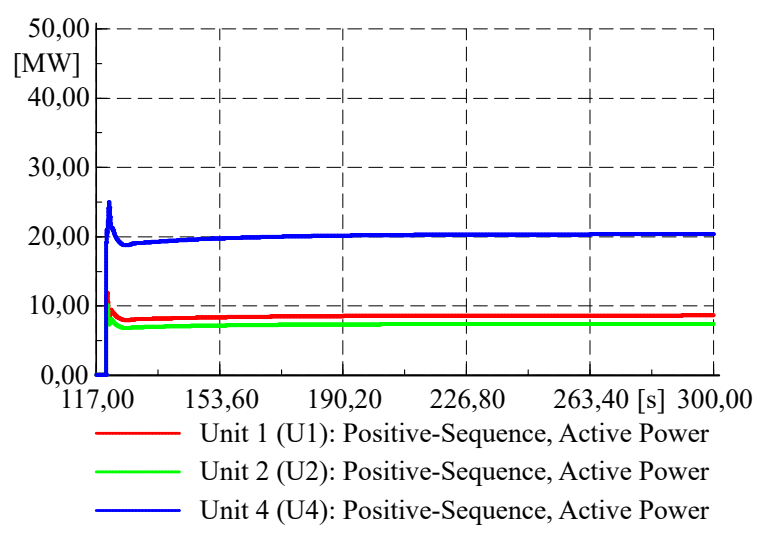

(b) Active power generation response.

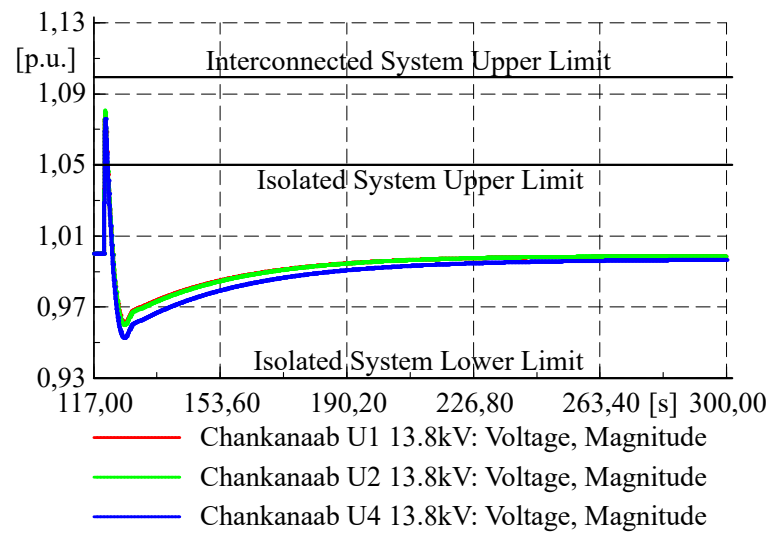

(c) Units busbar voltage response.

Figure 19: System response in a renewable production loss in a 100\% renewable generation grid in the Base Scenario in the virtual date: January 17th at 19:00 h by 2018 for Cozumel Island. 


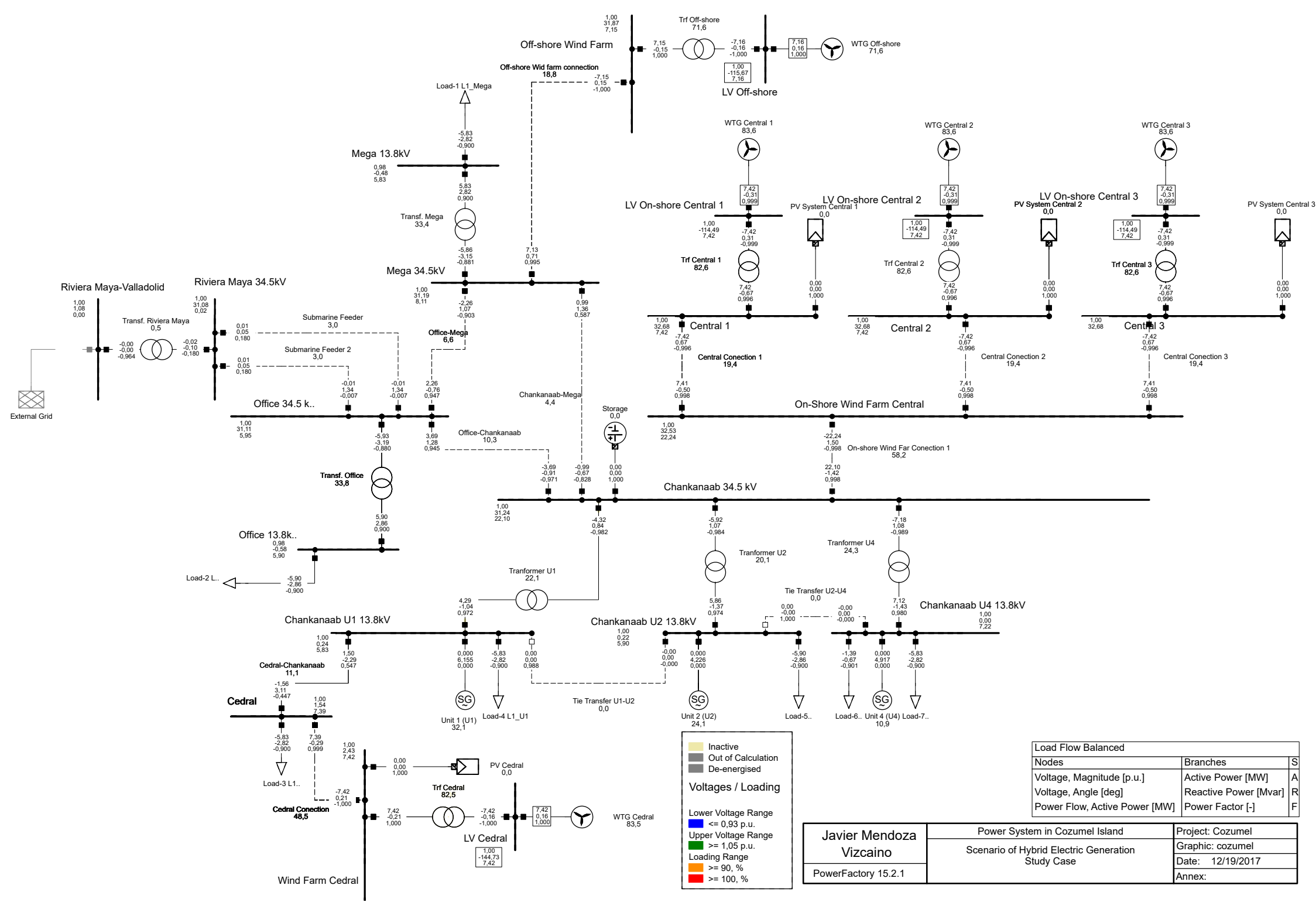

Figure 20: Chart of the electric system response in a 100\% renewable generation grid in the Base Scenario by 2018 for Cozumel Island, in the virtual date of January 17th at 19:00 h. 
A three phases failure is simulated and localized in the Chankanaab $34.5 \mathrm{kV}$ busbar. The system response is shown in Fig. 21. This figure also indicates the steady-state boundaries. This failure is simulated $10 \mathrm{~s}$ after the analysis was started, and it was cleared it after 0.150 ms, according to the MGC parameters. As it can be seen in this figure the voltage value returns within the time and limits allowed (area within the dotted lines). The continuous lines in the figure indicate the unlimited time allowed for the electric system in a steadystate operation. This simulation is made in the Base Scenario by 2018 and with the fossil fuel generation running (Fig. 21a). The power system response in the same scenario and year is analyzed when a $100 \%$ of renewable energy is supplying the power demand (Fig. 21b). The date of the dynamic simulation analysis for a fossil fuel generation grid (Fig. 21a) is September 11th at 22:00 h, at this time the system is running at $100 \%$ of maximum power demand. The date of the dynamic simulation analysis in a $100 \%$ renewable generation grid (Fig. 21b) is January 17 th at 19:00 h. At this time the system is supplying the $100 \%$ of the electricity on renewable power. In the same virtual date for the two options analyzed, Fig. 22 shows the frequency response resultant. This dynamic analysis is made in the Base Scenario by 2018 and with the fossil fuel generation running (Fig. 22a), also the frequency response in the same scenario and year, is analyzed when a $100 \%$ of renewable energy are supplying the power demand (Fig. 22b). In these figures, the frequency signal returns to a steady-state within the continuous values according to the MGC. Is important to indicate that these failure simulations were done in all scenarios and key years, and the results are very similar.

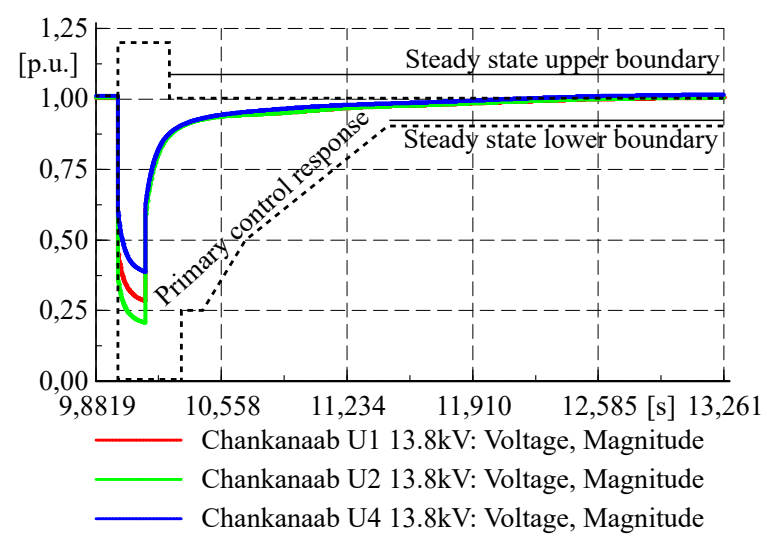

(a) Voltage response signal in a presence of a three phases fault.

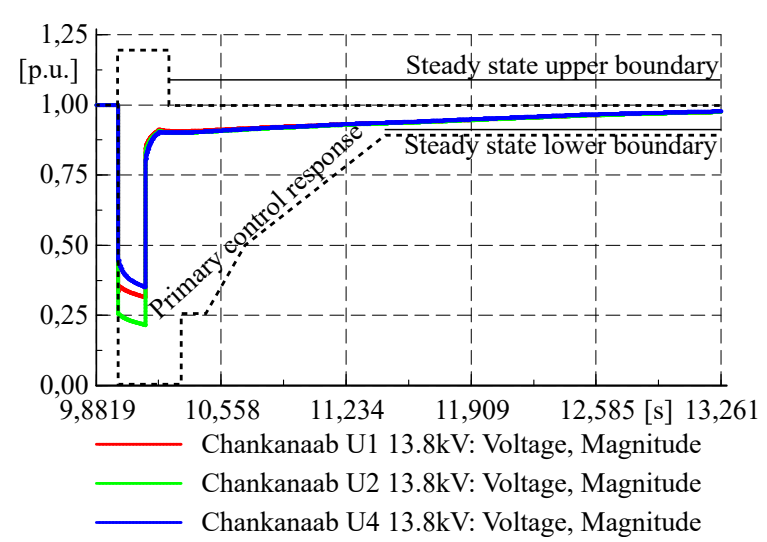

(b) Voltage response signal in a presence of a three phases fault.

Figure 21: Voltage response signal in a fossil fuel generation grid $(21 \mathrm{a})$ in the virtual date: September 11th at $22: 00 \mathrm{~h}$ by2018. Voltage response signal in a $100 \%$ renewable generation grid 21b in the virtual date: January 17th at 19:00 h by 2018. Both in the Base Scenario for Cozumel Island.

\section{Techno-economic analysis for the hybrid power system and the electric grid}

The NPC is the present value of all the costs of installing and operating the project over its lifetime minus the present value of all the revenues that it earns over the project lifetime. This is the results of the ratio of the annualized cost of the project and the capital recovery 


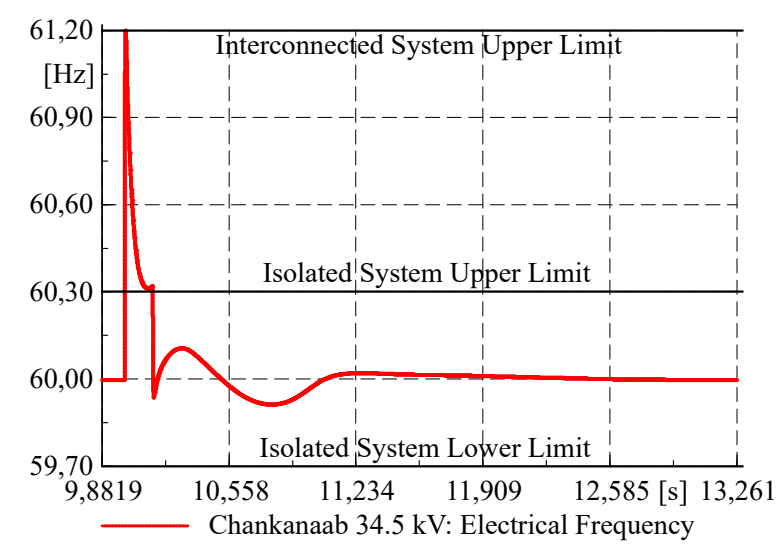

(a) Frequency response signal in a fossil fuel generation grid.

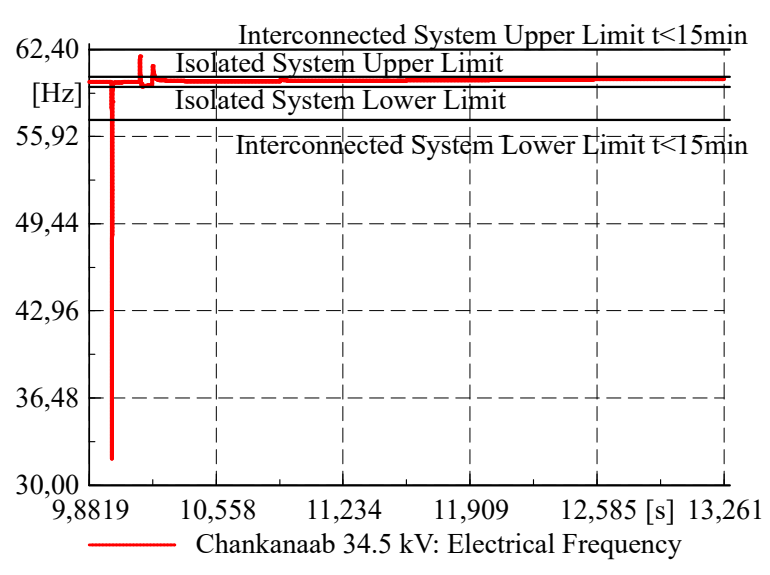

(b) Frequency response signal in a $100 \%$ renewable generation.

Figure 22: Frequency response signal in presence of a three phases fault in the Chankanaab busbar in 34.5 $\mathrm{kV}$, in a fossil fuel generation grid 22a (Virtual date: September 11th at 22:00 h by 2018), and in a 100\% renewable generation grid 22b (Virtual date: January 17th at 19:00 h by 2018) in the Base Scenario by 2018 for Cozumel Island.

factor. The annualized cost of a project is the cost that, if it were to occur equally in every year of the project lifetime, would give the same net present cost as the actual cash flow sequence associated with that project. For this two concepts, the less cost result, the more attractive for the investments will be. The capital recovery factor is a ratio used to calculate the present value of an annuity (a series of equal annual cash flows). The real discount rate is used to convert between one-time costs and annualized costs. The real discount rate is used to calculate discount factors and to calculate annualized costs from net present costs. The $\mathrm{LCOE}$ is considered as the average cost per $\mathrm{kWh}$ of useful electrical energy produced by the system. For this concept, also applies that the less cost result, the more attractive for the investments will be. To calculate the LCOE, the annualized cost of producing electricity is divided by the total electric load served. The RGF has the objective of guarantee the ICC, without the detriment of the IRR of the project. The RGF time is the result of the annual sum of the NPV annualized affected by the Retention Guarantee Rate (RGR). This yearly sum must be done until the RGF is equal to the ICC [37]. With this analysis, the money to be spent in case of a natural affectation to the renewable energy site will be done without impairment of the IRR.

The costs of the technologies used were obtained through the Energy Technology Reference Indicator projections for 2010-2050 [56] and the Materials Roadmap Enabling Low Carbon Energy Technologies of the European Commission [57]. Also, the technology costs indicated by Georgianne Huff et. al [58] have been considered as reference for this proposal. All the costs were changed to \$US 2016 constant and nominal money, taking into account the Consumer Price Index (CPI) [59] and the exchange rate published by the European Central Bank [60] from $€$ to US\$.

As results of the economic analysis done in section 3.2, figures Fig. 9, Fig. 10, Fig. 11 and Fig. 12 represent the ICC, the IRR, the RGF, the time for the RGF, the NPV, the NPC, the LCOE and how the ICC results change with the sensitivities applied. This analysis is made 
comparing the fossil fuel generation technology vs. the renewable generation technologies, including the storage bank. Each analysis is made for the three scenarios created in the four key years. An over-investment needs to be done in order to modify and reinforce the electric grid through the years, according to the growing perspectives outlined in Table 2 and Fig. 3. These over-investments are the result of the grid modification done in STEP 7 in PHASE 2 section 2.2, and in STEP 10 in Phase 3 section 2.3. As can be seen in Table 6, the fossil fuel generation grid changes and their cost appear in the middle part of this table. These over-investments are the result of the only fossil fuel operation through the years. Also, the hybrid generation grid changes and their cost appear in the right section of this table. These over-investments are the consecutive investments to be done on the electric grid depending on the way chosen to supply the electric demand chosen: only fossil fuel or hybrid system. The amount indicated for these changes is the quantity needed to have a reliable, strong and safe power system. As it can be seen in the lower part of Table 6, the total investments by 2050 are almost the same for each option. Therefore, integrate or not, the renewable electricity generation technologies will practically result in the same amount of money.

Table 6: 2018-2050 Over-investments summary for each Scenario in Cozumel Island.

Grid investments through key years for each Scenario

\begin{tabular}{ccrr}
\hline \hline Year & Scenarios & Fossil Generation & Hybrid Generation \\
\hline \multirow{2}{*}{ 2018 } & Low & 703,171 & $20,922,001$ \\
& Base & $8,770,145$ & $19,687,787$ \\
& High & $8,844,343$ & $20,996,199$ \\
\hline \multirow{2}{*}{ 024 } & Low & $10,141,164$ & $5,012,695$ \\
& Base & $14,284,204$ & $16,659,519$ \\
& High & $10,249,647$ & $12,782,832$ \\
\hline \multirow{2}{*}{ 035 } & Low & $27,182,972$ & $34,142,158$ \\
& Base & $27,549,120$ & $26,679,273$ \\
& High & $35,478,544$ & $32,972,858$ \\
\hline \multirow{2}{*}{ 050 } & Low & $38,580,382$ & $49,140,151$ \\
& Base & $61,339,979$ & $82,122,748$ \\
& High & $122,294,918$ & $113,774,477$ \\
\hline \hline \multirow{2}{*}{ 2018-2050 } & Total grid investments for each Scenario \\
& Low & $76,607,689$ & $109,217,005$ \\
& Base & $111,943,449$ & $145,149,327$ \\
\hline \hline
\end{tabular}

The total ICC for each year in the Base Scenario is indicated in Fig. 23a, where also the NPV and the RGF are showed. In this figure, the total cost of the project is indicated in two terms. The first, includes the power system cost obtained in the subsection 3.2 and the grid modifications done, as indicated in Table 6. The second term, is without considering the modification costs indicated in Table 6 and only considering the power system cost obtained in the subsection 3.2 . Fig. $23 \mathrm{~b}$ shows the IRR, the retention guarantee fund rate (RGFR) and the time to take the RFG to be equal with the ICC. These values include, in the first term, the power system cost obtained in subsection 3.2 and the grid modification done, as is indicated in Table 6. The second term does not consider the modification costs indicated in Table 6, it only considers the power system cost obtained in the subsection 3.2. In Fig. 23 the ICC, including the grid cost, will be obviously bigger than the ICC without it. Even so, 
the NPV, including the grid cost, is lower than the NPV without it. Normally, if the project would cost more, the value at the end of its lifetime should be smaller, but in this case, by 2050, the results show that is the opposite. Simultaneously, the IRR has the same results, because the new diesel turbines will be installed that year.

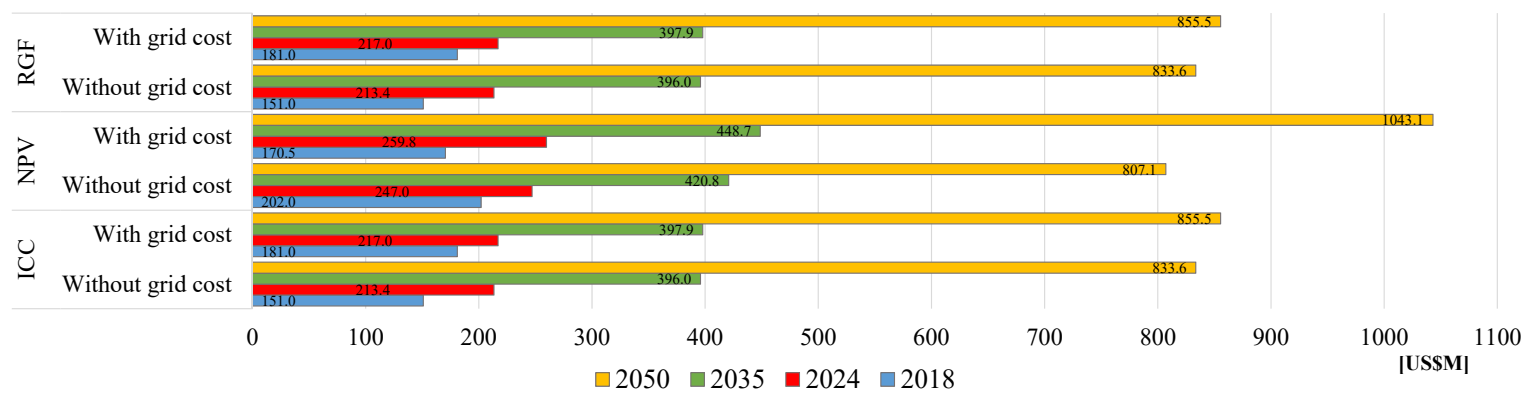

(a) ICC, NPV, and RGF results including and not including the grid cost in the ICC.

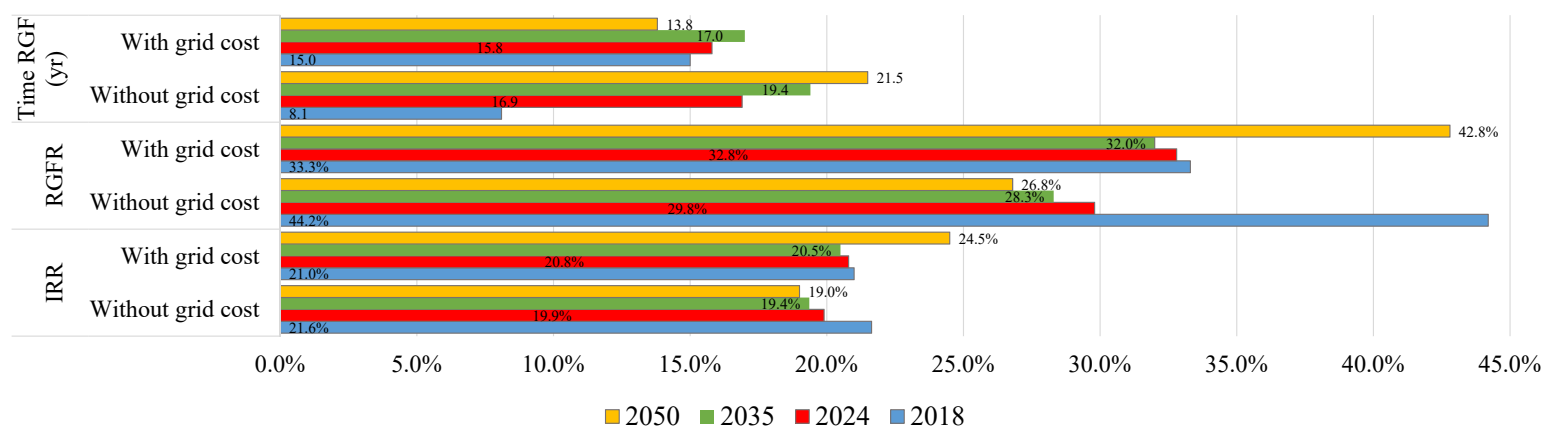

(b) IRR, RGFR, and time RGF results including and not including the grid cost in the ICC.

Figure 23: Economic results of include or not the grid modifications cost, in this case, without the sensitivities variables incorporated to the ICC in the Base Scenario by 2050 for Cozumel Island.

\section{1. $100 \%$ renewable energy supplying the electric load, a pre-analysis result}

This pre-analysis is elaborated in an attempt to visualize what combination of $\mathrm{PV} / \mathrm{Wind} /-$ Battery would be conformed to supply the $100 \%$ of the electric load for all the year in Cozumel Island, in the Base Scenario by 2050 this pre-analysis is elaborated. The initial input data is maintained, as well as the equipment cost for the renewable technology and for the diesel turbogas machine. Other considerations are maintained, like the sensitivities variables, the constrains and the inflation rate. Four system configurations are been settled and a fifth is taken as comparative: 1) system with the sensitivity variables applied; 2) system without the sensitivity variables applied; 3) system with the sensitivity variables applied and including the 8 wind turbines of 3 MW Off-shore resultant in the previous sections by 2050; 4) system without the sensitivity variables applied and including the 8 wind turbines of 3 MW Offshore resultant in the previous sections by 2050, and; 5) system with only diesel generation as comparative. Fig. 24, Fig. 25 and Fig. 26 show the results obtained. Fig. 24 indicates the system configurations to be install in four different combinations. As can be seen in this figure, the PV and Wind on-shore results are the same in the four configurations, this is because for each wind turbine will be installed $333.33 \mathrm{~kW}$ of PV. As the sensitivity variables 
includes only a PV efficiency improvement, there will be only a few production increasing. In two of them are including 8 off-shore turbines of $3 \mathrm{MW}$ each by 2050. The number of batteries and the converter capacity have to be increased for these two configuration. This will increase directly the NPC and the ICC and it will reduce the LCOE resultant, as it is shown in Fig. 25. In this figure, the LCOE for only diesel remains lower compared with the configuration without the sensitivity variables applied but is higher than those that apply these sensitivity variables. This is the result of the cost reduction and the efficiency increase applied. Finally, Fig. 26 shows the technical results of each configuration compared with the use of only diesel. These four configurations keep all the time the $100 \%$ of the renewable energy supplying the electric load without diesel consumption. In this figure is clear that there is not an electricity excess production in the diesel comparative configuration. This happens because that the fossil fuel machines can follow the electric load profile. The electricity excess produced in the first four configurations is due to the need to combine the three renewable technologies operations in order to supply all the electric load according to the electric load profile.

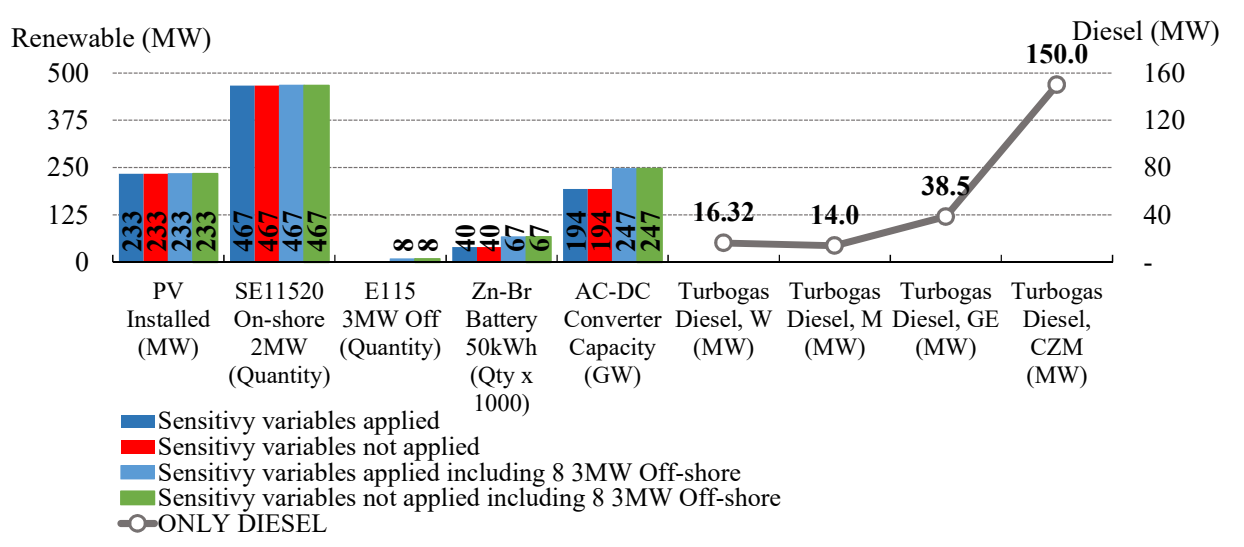

Figure 24: Equipment capacity installed in a 100\% renewable generation grid in the Base Scenario by 2050 for Cozumel Island.

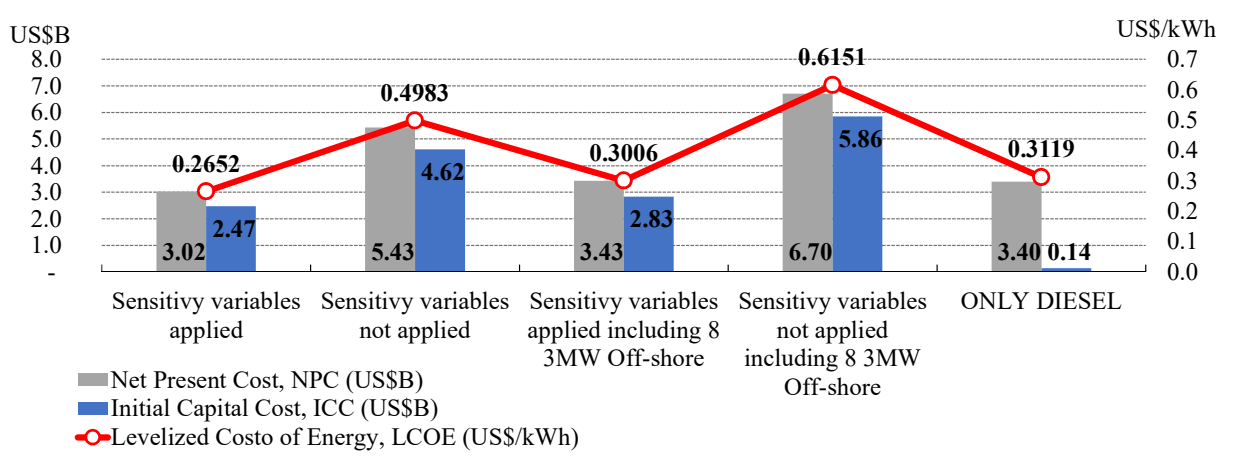

Figure 25: Economic results in a 100\% renewable generation grid in the Base Scenario by 2050 for Cozumel Island. 


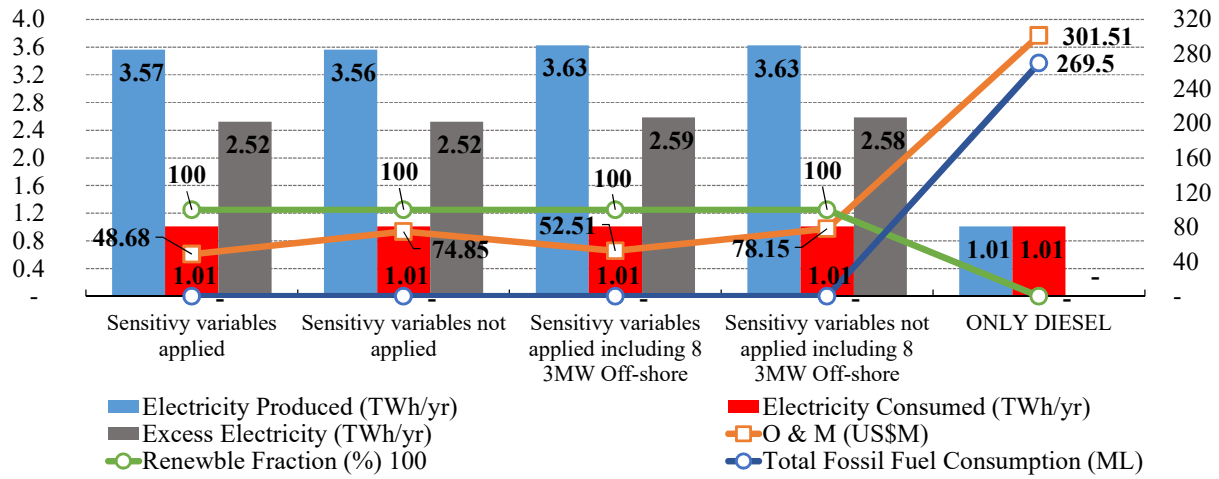

Figure 26: Technical results in a 100\% renewable generation grid in the Base Scenario by 2050 for Cozumel Island.

\section{Discussions}

The methodology proposed is validated on a real electric grid on a Caribbean Island by means of its application as a case of study. Always fulfilling the renewable energy targets in the REF generated for the electric system. This system has a reliable, strong and safe operation response even in case of a disturbance presence considering the continuous operation constraints based on the MGC parameters. Likewise, the sensitivity input values considered and the system response results to obtain a final technical proposal was analyzed and solved. All these technical results were the basis for the economic analysis and obtain the lowest LCOE, ICC and NPC, as well as the biggest NPV of the project suggested. As there is a long time planning evaluation, many thing can be changed over time. This methodology can apply several time-variables and the results will have enough certainty once the changes or risks are uploaded on it, then the new results can be compared against the originals and modify policies or initials statements. The sensitivity analysis can be done with garaties of a final and reliable outcomes. For instance, in a real case, the implementing of the renewable energy integration projects could take 7-15 years [51] [43], more or less. For this project, it will be selected 7 years for its implementation. This process must be done in the Energy Regulatory Commission (CRE, for its Spanish acronym) in Mexico. According to the CRE procedure time [61], if the project starts in 2017, it will be finished in 2024. In this year the investments should be applied and the project must be running. As the idea in this proposal is to have a modular system growing until 2050, and the Renewable Technology Equipment (RTE) lifetime average is 25 years, then all the RTE installed in 2024 will be substituted by new RTE in 2050. In 2035 the RTE installed in 2024 will still have a lifetime left to work, so that the new RTE quantity will be the difference of the total RTE considered to be installed in 2035 minus the existent RTE from the year 2024. In 2050 the RTE installed in 2024 will be replaced with new RTE, meanwhile, those that have been installed in 2035 will still be working and their replacement will be done after 10 years, approximately. The final investment in RTE to make by 2050 will be the difference of the total RTE considered being installed by 2050 minus the RTE installed in 2035. If something changes over time, the initial variables can be modified in order to adapt the modular growing of the system to the new parameters. Table 7 shows these investments over the key years, considering the RTE quantities as investments. In this table, the grey areas belong to the newly installed 
equipment that will need to be installed in each indicated key year

Table 7: New Renewable Technology Equipment (RTE) to install (grey areas) in each key year starting in 2024 in the Base Scenario for Cozumel Island.

\begin{tabular}{ccccccc} 
& PV & $\begin{array}{c}\text { SE11520 } \\
\text { 2MW } \\
\text { (Quantity) }\end{array}$ & $\begin{array}{c}\text { E115 } \\
\text { 3MW }\end{array}$ & $\begin{array}{c}\text { Battery } \\
\text { (Quantity) }\end{array}$ & $\begin{array}{c}\text { DC-AC } \\
\text { Converter } \\
\text { (Quantity) }\end{array}$ & \begin{tabular}{c} 
(MW) \\
\hline \hline 2024
\end{tabular} \\
\hline \multirow{2}{*}{2035} & 13.0 & 21 & 5 & 548 & 27.4 \\
2050 & 34.7 & 104 & 8 & 1943 & 97.2 \\
\hline \hline \multirow{2}{*}{2035} & Existent & 7.0 & 21 & 5 & 548 & 27.4 \\
& New & 6.0 & 18 & 3 & 352 & 17.6 \\
\hline \multirow{2}{*}{2050} & Existent & 6.0 & 18 & 3 & 352 & 17.6 \\
& New & 28.7 & 86 & 5 & 1591 & 79.6 \\
\hline
\end{tabular}

From Fig. 26, it can be seen that there is a huge potential to interconnect electric vehicles taking advantage of the electricity excess production. With the right policies, Cozumel Island's Government can activate cleaner energy strategies for the public transport sector, changing fossil fuel vehicles to electric vehicles, for instance. Even the private transport sector could be benefited by this electricity excess production. This is one of the most interesting points to be developed in Cozumel Island, discussions held with government personnel have confirmed that the results seem to be very attractive to carry it out, for them. For future works, it can develop the analysis of how many gasoline vehicles can be substitute by electric vehicles and which control side demand will be the optimum, in order to utilize all the electricity excess production on the Island. The classification of global small islands gives the overview that in many of them the RES implementation can carry out with significant and positive results on it. Therefore, it supports the transfer of proven, well-working concepts and the direct adoption of these concepts by suitable islands. The work of Meschede et al. is applied in those islands that are very similar to Cozumel Island and the islands which have especially high potentials for the use of a specific renewable energy source can be easily recognized [62]. Despite this similar characteristics, this work is not similar, because in this document the integral analysis of the RE implementation in a existing fossil fuel generation grid is carried out. It includes: a) RETs integration and combination (PV/Wind/Battery); b) Power flow analysis and quasy-dynamic simulations; c) Grid reinforcements and modifications proposed, applied and validated in a real current electric grid in a small island; d) a dynamic analysis to assess the strong and safe grid response in case of fault or system unbalance getting back to the original steady state operation, and; e) a complete financial analysis including the grid modifications and reinforcements costs did through time until 2050; all this without detriment of the renewable fraction of electricity integrated and fulfilling the Mexican Grid Code in its operation.

This work results match with results published by Gioutsos et al. in some aspects [63]. One of the most important of them is that with the results in the levelized cost of systems for electricity generation decrease considerably with increasing renewable energy penetrations, to an optimal point in the range of $40 \%$ to $80 \%$ penetration. Likewise, this work match with the RETs including in the simulations as Adefarati and Bansal show in their work, where present a comprehensive reliability assessment of the distribution system that satisfies the 
consumer load requirements with the penetration of wind turbine generator, electric storage system and photovoltaic [16]. In this proposal, like theirs, the results obtained from the case studies have demonstrated the effectiveness of using Wind/PV/Batt to enhance the reliability of the conventional distribution system. Same results presented by Sigrist et al. [10] gives a clear idea that the results showed by this document has enough certainty and validation to be applied by other small islands in every tropical region of the world.

Small Tropical Islands share a lot of common things between them, as can be: weather, fossil fuel generation of electricity, off-grid operation, tourism high dependence and sensitive environmental, among others. According to Blechinger et al. almost 1800 islands with approximately 20 million inhabitants currently supplied by $15 \mathrm{GW}$ of diesel plants [1]. With the proper regulations can be accelerated the implementation of this enormous potential, so this document can be a good mechanism for it, once that includes a renewable energy integration analysis, a grid assessment and its response analysis in a steady and dynamic state, grid modifications through time and a financial analysis to obtain the appropriate resultant system to be installed on Cozumel Island.

\section{Conclusions}

This paper proposes an integral methodology to study a renewable power system integration and performs a grid assessment, in order to achieve the energy planning within the National legal framework, that includes the renewable energy targets to be fulfilled until 2050. Therefore, to do it in an optimal manner and to accomplish the renewable energy target, in this study was optimized and to reduced the backup time of the battery system, and was compared four different battery technologies, simultaneously. This methodology is validated in the small Caribbean island of Cozumel, Mexico, and it focuses on the electric grid response (according to the MGC) where the renewable electricity generation is integrated into an real operating fossil fuel generation grid.

1. As the results show, the Zinc-Bromine battery bank included in the initial hybrid system selected is the best battery technology resultant.

2. From the four different battery bank technologies selected to compare the complete power system response and grid behaviour, the Zinc-Bromine redox flow battery showed the best results, both economically and technically for all scenarios and through the four key years until 2050. With the sensitivity variables (cost reduction and the increasing efficiency parameters) included in the analysis, these results were even better by 2050 .

3. Combining this battery bank with the diesel turbogas machines, the wind turbines placed off-shore and on-shore and the PV array the economic results were the lowest LCOE, ICC and NPC and the biggest NPV from the system combination studied, as Table 8 shows:

4. From the steady-state power flow analysis results, the voltage and loading values from using only the fossil fuel generation or from using the hybrid power generation showed a huge difference. Despite the variations in the equipment operation respect to the load profile, the performance in the hybrid grid resultant was improved and the system response made visible that the system turned reliable, strong and safe. 
Table 8: Final LCOE in the Base Scenario by 2018

\begin{tabular}{|c|c|c|c|c|c|c|c|c|}
\hline $\begin{array}{c}\text { Diesel } \\
\text { Turbogas } \\
(\mathrm{MW})\end{array}$ & $\begin{array}{l}\text { Off-shore } \\
\text { turbine } \\
(\mathrm{MW})\end{array}$ & $\begin{array}{c}\text { On-shore } \\
\text { turbine } \\
(\mathrm{MW})\end{array}$ & $\begin{array}{c}\text { PV } \\
(\mathrm{MW})\end{array}$ & $\begin{array}{c}\text { DC-AC } \\
\text { Converter } \\
(\mathrm{MW})\end{array}$ & $\begin{array}{l}\text { Battery } \\
(\mathrm{MWh})\end{array}$ & $\begin{array}{l}\text { Battery } \\
\text { (Type) }\end{array}$ & $\begin{array}{l}\text { LCOE } \\
(\$ U S)\end{array}$ & $\begin{array}{c}\text { Renewable } \\
\text { Fraction } \\
(\%)\end{array}$ \\
\hline 58.32 & 27 & 64 & 5.4 & 20.95 & 20.95 & $\mathrm{Zc}-\mathrm{Br}$ & 0.2417 & $43 \%$ \\
\hline 58.32 & 36 & 64 & 5. & 20.7 & 20.77 & Vanadium & 0.2440 & $43 \%$ \\
\hline 58.32 & 36 & 60 & 5.0 & 31.60 & 31.60 & Ion-Lithium & 0.2442 & $44 \%$ \\
\hline 58.32 & 36 & 64 & 5.4 & 21.54 & 21.54 & Lead-Acid & 0.2446 & $44 \%$ \\
\hline
\end{tabular}

5. In the voltage results with only fossil fuel generation the furthest busbar, called Cedral in $13.8 \mathrm{kV}$ had a value of $0.983 \mathrm{p} . \mathrm{u}$. as a maximum and $0.931 \mathrm{p} . \mathrm{u}$. as a minimum (always within the MGC parameters for a continuous operation). With the hybrid generation, the voltage result for this busbar was 1.013 p.u. as a maximum and 0.946 p.u. as a minimum. These results were obtained once the electric grid was modified and reinforced (see Table 4 and Table 6), and they were performed in the Base Scenario by 2018.

6. The results from the dynamic analysis showed that the final power system is strong enough to have a response within the MGC parameters, once the modifications and reinforcements were done. In both, fossil fuel generation grid and hybrid power generation grid.

7. The dynamic analysis response of the power system accomplishes the primary control response to maintain a stable and continuous operation, according to the grid code mentioned.

8. Theoretically by 2035, 8 off-shore wind turbines of $3 \mathrm{MW}$ of capacity each one in combination with $13 \mathrm{MW}$ of PV, 39 on-shore $2 \mathrm{MW}$ wind turbines, and $900 \mathrm{Zn}-\mathrm{Br}$ redox flow batteries of $50 \mathrm{kWh}$ each must be installed. As by 2050, the best result shows that no off-shore wind turbine would be installed, a final combination has been proposed: 8 off-shore $3 \mathrm{MW}$ wind turbines, 104 on-shore $2 \mathrm{MW}$ wind turbines combined with 34.7 MW of PV total array, 1,943 Zn-Br redox flow batteries of $50 \mathrm{kWh}$ each and 97.15 MW of DC-AC converter capacity. As by 2035, the off-shore connection must be included in the techno-economic analysis, this underground lines and protection equipment will be used for the 2050 off-shore wind farm to be installed.

9. For Cozumel Island's electric grid (without the power generation technologies), the results in the total investments in the High Scenario in 2050 are almost the same for each option (both, fossil fuel generation grid or hybrid generation grid). Integrate or not, the renewable electricity generation technologies will result in the same amount of money invested (see Table 6).

10. Finally, from the pre-analysis elaborated to supply the $100 \%$ of the electric demand with renewable electricity on the island, results show that this can be done using the diesel machines only to keep the reliability on the grid, supplying the reactive power need it to maintain the system in balance. This can be changed substituting the diesel machines by Voltage Source Converters (VSC). This solution can be developed for future works, taking into account that the research demonstrates the converter ability to control the distribution of power among the transmission system while ensuring the network stability [64]. 


\section{Acknowledgment}

The author would like to acknowledge the support of Consejo Nacional de Ciencia y Tecnologa (CONACYT) in this work through the financial support of scholarship ID 437020. The author would also like to thank the kind collaboration of Mr Rafael Cervera Casanueva in the proofreading of the text.

\section{References}

[1] P. Blechinger, C. Cader, P. Bertheau, H. Huyskens, R. Seguin, C. Breyer, Global analysis of the techno-economic potential of renewable energy hybrid systems on small islands, Energy Policy 98 (2016) 674-687. doi:10.1016/j.enpol.2016.03.043. URL http://dx.doi.org/10.1016/j.enpol.2016.03.043http://linkinghub. elsevier.com/retrieve/pii/S0301421516301471

[2] A. Alqurashi, A. H. Etemadi, A. Khodaei, Treatment of uncertainty for next generation power systems: State-of-the-art in stochastic optimization, Electric Power Systems Research 141 (2016) 233-245. doi:10.1016/j.epsr.2016.08.009. URL http://dx.doi.org/10.1016/j.epsr.2016.08.009http://linkinghub. elsevier.com/retrieve/pii/S0378779616303017

[3] A. Maleki, M. G. Khajeh, M. Ameri, Optimal sizing of a grid independent hybrid renewable energy system incorporating resource uncertainty, and load uncertainty, International Journal of Electrical Power \& Energy Systems 83 (2016) 514-524. doi:10.1016/j.ijepes.2016.04.008. URL http://dx.doi.org/10.1016/j.ijepes.2016.04.008http://linkinghub. elsevier.com/retrieve/pii/S0142061516306408

[4] J. Mendoza-Vizcaino, A. Sumper, S. Galceran-Arellano, PV, Wind and Storage Integration on Small Islands for the Fulfilment of the 50-50 Renewable Electricity Generation Target, Sustainability 9 (12) (2017) 905. doi:10.3390/su9060905.

URL http: //www .mdpi .com/2071-1050/9/6/905

[5] P. Stenzel, A. Schreiber, J. Marx, C. Wulf, M. Schreieder, L. Stephan, Renewable energies for Graciosa Island, Azores Life Cycle Assessment of electricity generation, Energy Procedia 135 (2017) 62-74. doi:10.1016/j.egypro.2017.09.487. URL https://doi.org/10.1016/j.egypro.2017.09.487http://linkinghub. elsevier.com/retrieve/pii/S1876610217345903

[6] H. C. Gils, S. Simon, Carbon neutral archipelago $100 \%$ renewable energy supply for the Canary Islands, Applied Energy 188 (2017) 342-355. doi:10.1016/j.apenergy.2016.12.023.

URL http://dx.doi.org/10.1016/j.apenergy.2016.12.023http://linkinghub. elsevier.com/retrieve/pii/S0306261916317871

[7] M. Child, A. Nordling, C. Breyer, Scenarios for a sustainable energy system in the Åland Islands in 2030, Energy Conversion and Management 137 (2017) 49-60. 
doi:10.1016/j.enconman.2017.01.039.

URL http://dx.doi.org/10.1016/j.enconman.2017.01.039http://linkinghub. elsevier.com/retrieve/pii/S019689041730047X

[8] D. Nikolic, T. Tereapii, W. Y. Lee, C. Blanksby, Cook Islands: 100\% Renewable Energy in Different Guises, Energy Procedia 103 (April) (2016) 207-212. doi:10.1016/j.egypro.2016.11.274.

URL http://dx.doi.org/10.1016/j.egypro.2016.11.274http://linkinghub. elsevier.com/retrieve/pii/S1876610216314849

[9] A. Khoodaruth, V. Oree, M. Elahee, W. W. Clark, Exploring options for a 100\% renewable energy system in Mauritius by 2050, Utilities Policy 44 (2017) 38-49. doi: 10.1016/j.jup.2016.12.001.

URL http://linkinghub.elsevier.com/retrieve/pii/S0957178716303642

[10] L. Sigrist, E. Lobato, L. Rouco, M. Gazzino, M. Cantu, Economic assessment of smart grid initiatives for island power systems, Applied Energy 189 (2017) 403-415. doi: 10.1016/j.apenergy.2016.12.076.

URL http://linkinghub.elsevier.com/retrieve/pii/S0306261916318372

[11] Y. Zhang, A. Lundblad, P. E. Campana, F. Benavente, J. Yan, Battery sizing and rule-based operation of grid-connected photovoltaic-battery system: A case study in Sweden, Energy Conversion and Management 133 (2017) 249-263. doi:10.1016/j.enconman.2016.11.060.

URL http://dx.doi.org/10.1016/j.enconman.2016.11.060http://linkinghub. elsevier.com/retrieve/pii/S019689041631069X

[12] M. Obi, S. Jensen, J. B. Ferris, R. B. Bass, Calculation of levelized costs of electricity for various electrical energy storage systems, Renewable and Sustainable Energy Reviews 67 (2017) 908-920. doi:10.1016/j.rser.2016.09.043.

URL http://dx.doi.org/10.1016/j.rser.2016.09.043http://linkinghub. elsevier.com/retrieve/pii/S136403211630524X

[13] R. Dufo-López, I. R. Cristóbal-Monreal, J. M. Yusta, Stochastic-heuristic methodology for the optimisation of components and control variables of PV-wind-diesel-battery stand-alone systems, Renewable Energy 99 (2016) 919-935. doi:10.1016/j.renene. 2016.07.069.

URL http://linkinghub.elsevier.com/retrieve/pii/S096014811630684X

[14] S. Kwon, W. Won, J. Kim, A superstructure model of an isolated power supply system using renewable energy: Development and application to Jeju Island, Korea, Renewable Energy 97 (2016) 177-188. doi:10.1016/j.renene.2016.05.074.

URL http://dx.doi.org/10.1016/j.renene.2016.05.074http://linkinghub. elsevier.com/retrieve/pii/S0960148116304840

[15] S. Szabó, I. Kougias, M. Moner-Girona, K. Bódis, Sustainable Energy Portfolios for Small Island States, Sustainability 7 (12) (2015) 12340-12358. doi:10.3390/ 
su70912340.

URL http: //www .mdpi.com/2071-1050/7/9/12340/

[16] T. Adefarati, R. Bansal, Reliability assessment of distribution system with the integration of renewable distributed generation, Applied Energy 185 (2017) 158-171. doi:10.1016/j.apenergy.2016.10.087.

URL http://dx.doi.org/10.1016/j.apenergy.2016.10.087http://linkinghub. elsevier.com/retrieve/pii/S0306261916315318

[17] P. Wijayatunga, L. George, A. Lopez, J. A. Aguado, Integrating Clean Energy in Small Island Power Systems: Maldives Experience, Energy Procedia 103 (April) (2016) 274-279. doi:10.1016/j.egypro.2016.11.285.

URL http://dx.doi.org/10.1016/j.egypro.2016.11.285http://linkinghub. elsevier.com/retrieve/pii/S1876610216314953

[18] M. Koepke, S. Groh, Against the Odds: The Potential of Swarm Electrification for Small Island Development States, Energy Procedia 103 (April) (2016) 363-368. doi:10.1016/j.egypro.2016.11.300.

URL http://dx.doi.org/10.1016/j.egypro.2016.11.300http://linkinghub. elsevier.com/retrieve/pii/S1876610216315107

[19] L. Sheng, Z. Zhou, J. Charpentier, M. Benbouzid, Stand-alone island daily power management using a tidal turbine farm and an ocean compressed air energy storage system, Renewable Energy 103 (2017) 286-294. doi:10.1016/j.renene.2016.11.042. URL http://dx.doi.org/10.1016/j.renene.2016.11.042http://linkinghub. elsevier.com/retrieve/pii/S0960148116310114

[20] C. Shang, D. Srinivasan, T. Reindl, Generation-scheduling-coupled battery sizing of stand-alone hybrid power systems, Energy 114 (2016) 671-682. doi:10.1016/j.energy.2016.07.123.

URL http://dx.doi.org/10.1016/j.energy.2016.07.123http://linkinghub. elsevier.com/retrieve/pii/S0360544216310477

[21] M. Miguel, T. Nogueira, F. Martins, Energy storage for renewable energy integration: the case of Madeira Island, Portugal, Energy Procedia 136 (2017) 251-257. doi:10.1016/j.egypro.2017.10.277.

URL https://doi.org/10.1016/j.egypro.2017.10.277http://linkinghub. elsevier.com/retrieve/pii/S187661021735227X

[22] A. Setas Lopes, R. Castro, J. Ferreira de Jesus, Contributions to the preliminary assessment of a Water Pumped Storage System in Terceira Island (Azores), Journal of Energy Storage 6 (2016) 59-69. doi:10.1016/j.est.2016.01.009. URL http://dx.doi.org/10.1016/j.est.2016.01.009http://linkinghub. elsevier.com/retrieve/pii/S2352152X16300093

[23] J. Fleer, P. Stenzel, Impact analysis of different operation strategies for battery energy storage systems providing primary control reserve, Journal of Energy Storage 8 (2015) 
(2016) 320-338. doi:10.1016/j.est.2016.02.003.

URL http://dx.doi.org/10.1016/j.est.2016.02.003http://linkinghub.

elsevier.com/retrieve/pii/S2352152X16300123

[24] C. Bordin, H. O. Anuta, A. Crossland, I. L. Gutierrez, C. J. Dent, D. Vigo, A linear programming approach for battery degradation analysis and optimization in offgrid power systems with solar energy integration, Renewable Energy 101 (2017) 417-430. doi:10.1016/j.renene.2016.08.066.

URL http://dx.doi.org/10.1016/j.renene.2016.08.066http://linkinghub. elsevier.com/retrieve/pii/S0960148116307765

[25] D. Rosewater, A. Williams, Analyzing system safety in lithium-ion grid energy storage, Journal of Power Sources 300 (2015) 460-471. doi : 10.1016/j . jpowsour .2015.09.068. URL http://dx.doi.org/10.1016/j.jpowsour.2015.09.068http://linkinghub. elsevier.com/retrieve/pii/S037877531530327X

[26] C. Taliotis, E. Taibi, M. Howells, H. Rogner, M. Bazilian, M. Welsch, Renewable energy technology integration for the island of Cyprus: A cost-optimization approach, Energy 137 (2017) 31-41. doi:10.1016/j.energy.2017.07.015.

URL https://doi.org/10.1016/j.energy.2017.07.015http://linkinghub. elsevier.com/retrieve/pii/S036054421731191X

[27] E. Taibi, G. Gualberti, M. Bazilian, D. Gielen, A framework for technology cooperation to accelerate the deployment of renewable energy in Pacific Island Countries, Energy Policy 98 (2016) 778-790. doi:10.1016/j.enpol.2016.03.009.

URL http://dx.doi.org/10.1016/j.enpol.2016.03.009http://linkinghub. elsevier.com/retrieve/pii/S0301421516301100

[28] S. Simoes, W. Nijs, P. Ruiz, A. Sgobbi, C. Thiel, Comparing policy routes for lowcarbon power technology deployment in EU an energy system analysis, Energy Policy 101 (December 2015) (2017) 353-365. doi:10.1016/j.enpol.2016.10.006.

[29] J.-H. Lin, Y.-K. Wu, H.-J. Lin, Successful Experience of Renewable Energy Development in Several Offshore Islands, Energy Procedia 100 (September) (2016) 8-13. doi:10.1016/j.egypro.2016.10.137.

URL http://dx.doi.org/10.1016/j.egypro.2016.10.137http://linkinghub. elsevier.com/retrieve/pii/S1876610216310980

[30] I. Staffell, M. Rustomji, Maximising the value of electricity storage, Journal of Energy Storage 8 (2016) 212-225. doi:10.1016/j.est.2016.08.010.

URL http://dx.doi.org/10.1016/j.est.2016.08.010http://linkinghub. elsevier.com/retrieve/pii/S2352152X1630113X

[31] G. Shafiullah, Hybrid renewable energy integration (HREI) system for subtropical climate in Central Queensland, Australia, Renewable Energy 96 (2016) 1034-1053. doi:10.1016/j.renene.2016.04.101.

URL http://linkinghub.elsevier.com/retrieve/pii/S0960148116304220 
[32] L. K. Gan, J. K. Shek, M. A. Mueller, Optimised operation of an off-grid hybrid winddiesel-battery system using genetic algorithm, Energy Conversion and Management 126 (2016) 446-462. doi:10.1016/j .enconman.2016.07.062.

URL http://dx.doi.org/10.1016/j.enconman.2016.07.062http://linkinghub. elsevier.com/retrieve/pii/S0196890416306409

[33] B. Muruganantham, R. Gnanadass, N. Padhy, Challenges with renewable energy sources and storage in practical distribution systems, Renewable and Sustainable Energy Reviews 73 (2017) 125-134. doi:10.1016/j.rser.2017.01.089.

URL http://linkinghub.elsevier.com/retrieve/pii/S1364032117301004

[34] United Nations Framework Convention on Climate Change, Paris Agreement - Status of Ratification (2017).

URL http://unfccc.int/paris\{_\}agreement/items/9444.php

[35] DIgSILENT GmbH, Power Factory 15, User Manual (2014).

[36] DIgSILENT GmbH, Power System Stability, Training Course (2017).

URL https://www.digsilent.de/en/seminars/content/pdf_seminars/ PowerSystemStability.pdf

[37] R. Serrahima Formosa, La valoración de proyectos de inversión productiva. (2017).

URL http://raimon. serrahima.com/

[38] C. R. d. E. (CRE), RESOLUCIÓN por la que la Comisión Reguladora de Energía expide las Disposiciones Administrativas de carácter general que contienen los criterios de eficiencia, calidad, confiabilidad, continuidad, seguridad y sustentabilidad del Sistema Eléctrico Nacional (2016).

URL http://www.dof.gob.mx/nota\{_\}detalle.php?codigo=5432507\{\&\}fecha=08/ $04 / 2016$

[39] HOMER Energy LLC, HOMER microgrid white papers (2017).

URL http://microgridnews . com/microgrid-white-papers/

[40] HOMER Energy LLC, HOMER energy (2017).

URL www . homerenergy.com/HOMER\{_\}pro.html

[41] R. R. D. C. (NREL), National Renewable Energy Laboratory; (RReDC), Renewable Resource Data Center (2017).

URL https://www.nrel.gov/rredc/

[42] P. o. W. E. R. P. N. (POWER), Surface meteorology and Solar Energy (2017).

URL https://eosweb.larc.nasa.gov/sse/

[43] S. Secretaría de Energía, Development Program for the National Electric System (PRODESEN) 2016-2030 PART II, Tech. rep., Secretaría de Energía, Mexico City, Mexico (2016).

URL

https://www.gob.mx/sener/acciones-y-programas/ programa-de-desarrollo-del-sistema-electrico-nacional-33462?idiom=es 
[44] H. Energy LLC, HOMER PRO Ver. 3.9 (2017).

URL wWw . homerenergy . com

[45] S. Salehin, M. T. Ferdaous, R. M. Chowdhury, S. S. Shithi, M. B. Rofi, M. A. Mohammed, Assessment of renewable energy systems combining techno-economic optimization with energy scenario analysis, Energy 112 (2016) 729-741. doi : 10.1016/j .energy . 2016.06.110.

URL http://linkinghub.elsevier .com/retrieve/pii/S0360544216308842

[46] M. Baneshi, F. Hadianfard, Techno-economic feasibility of hybrid diesel/PV/wind/battery electricity generation systems for non-residential large electricity consumers under southern Iran climate conditions, Energy Conversion and Management 127 (2016) 233-244. doi:10.1016/j.enconman.2016.09.008.

URL http://dx.doi.org/10.1016/j.enconman.2016.09.008http://linkinghub. elsevier.com/retrieve/pii/S0196890416307877

[47] A. Spisto, N. Hrelja, The Economic and Environmental Assessment of Electricity Storage Investments. Any Need for Policy Incentives?, Energy Procedia 106 (2016) 122-133. doi:10.1016/j.egypro.2016.12.110.

URL https://www.sciencedirect.com/science/article/pii/ S187661021631668Xhttp://linkinghub.elsevier.com/retrieve/pii/ S187661021631668X

[48] L. Ali, F. Shahnia, Determination of an economically-suitable and sustainable standalone power system for an off-grid town in Western Australia, Renewable Energy 106 (2017) 243-254. doi:10.1016/j.renene.2016.12.088.

URL http://dx.doi.org/10.1016/j.renene.2016.12.088http://linkinghub. elsevier.com/retrieve/pii/S0960148116311533

[49] M. Hossain, S. Mekhilef, L. Olatomiwa, Performance evaluation of a standalone PV-wind-diesel-battery hybrid system feasible for a large resort center in South China Sea, Malaysia, Sustainable Cities and Society 28 (2017) 358-366. doi:10.1016/j.scs.2016.10.008.

URL http://dx.doi.org/10.1016/j.scs.2016.10.008http://linkinghub. elsevier.com/retrieve/pii/S2210670716302670

[50] R. Clark, A Predictive Optimal Dispatch and Optimal Sizing Method for a System Declaration of Authorship, Master of science in engineering thesis, University of the Witwatersrand, Johannesburg (2014).

[51] S. Secretaría de Energía, Development Program for the National Electric System (PRODESEN) 2016-2030 PART I, Tech. rep., Secretaría de Energía, Mexico, D.F. (2016).

URL

https://www.gob.mx/sener/acciones-y-programas/ programa-de-desarrollo-del-sistema-electrico-nacional-33462?idiom=es

[52] M. Raza, Load Flow Calculation and Its Application, in: PowerFactory Applications for Power System Analysis., Springer, Cham, 2014, Ch. 1, pp. 1-25. doi:10.1007/ 
978-3-319-12958-7_1.

URL http://link . springer.com/10.1007/978-3-319-12958-7\{_\}1

[53] N. P. T. E. L. (NPTEL), Lecture 5, Basic Newton - Raphson (NR) Techniques (2017). URL http://nptel.ac.in/courses/108107028/module2/lecture5/lecture5.pdf

[54] J. C. Munoz Guerrero, Affine Arithmetic Based Methods for Power Systems Analysis Considering Intermittent Sources of Power, Ph.D. thesis, University of Waterloo (2014). URL https://uwspace.uwaterloo.ca/handle/10012/8161

[55] M. Diao, R; Wang, S; Samaan, NA; Dagle, JE; Makarov, YV; Vallem, MR; Nguyen, TB; Miller, LE; Vyakaranam, BG; Tuffner, FK; Pai, Dynamic Contingency Analysis Tool Phase 1, Tech. Rep. November, Pacific Northwest National Laboratory-DOE, Richland, Washington (2015).

URL https : //www .pnnl .gov/main/publications/external/technical\{_\}reports/ PNNL-24843.pdf

[56] JRC (Joint Research Centre of the European Commissio), Energy Technology Reference Indicator projections for 2010-2050, Tech. rep., Institute for Energy and Transport of the Joint Research Centre of the European Commission, Petten, Netherlands (2014). doi:10.2790/057687.

URL https://setis.ec.europa.eu/system/files/ETRI2014.pdf

[57] European Comission, Materials roadmap enablig low carbon energy technologies, Tech. rep., EUROPEAN COMMISSION, Brussels (2011).

URL https://ec.europa.eu/research/industrial\{_\}technologies/pdf/ materials-roadmap-elcet-13122011\{_\}en.pdf

[58] G. Huff, A. B. Currier, B. C. Kaun, D. M. Rastler, S. B. Chen, D. T. Bradshaw, W. D. Gauntlett, A. L. Cotter, A. A. Akhil, DOE/EPRI 2013 electricity storage handbook in collaboration with NRECA, Tech. Rep. July, Sandia National Laboratories, Livermore, California (2013).

URL http://www.emnrd.state.nm.us/ECMD/RenewableEnergy/documents/ SNL-ElectricityStorageHandbook2013.pdf

[59] Global Rates, Global Rate. Consumer Price Index (2017).

URL http://es.global-rates.com/estadisticas-economicas/inflacion/ indice-de-precios-al-consumo/ipc/estados-unidos.aspx

[60] European Central Bank, European Central Bank. Euros vs USD exchange rate. (2017). URL https://www.ecb.europa.eu/stats/policy\{_\}and\{_\}exchange\{_\}rates/ euro\{_\}reference\{_\}exchange\{_\}rates/html/eurofxref-graph-usd.en.html

[61] CENACE (Centro Nacional de Control de Energía), CRITERIOS mediante los que se establecen las características específicas de la infraestructura requerida para la Interconexión de Centrales Eléctricas y Conexión de Centros de Carga., Tech. rep., Centro Nacional de Control de Energía (CENACE), Mexico City, Mexico (2015).

URL

http://www.cenace.gob.mx/Docs/MarcoRegulatorio/ 
CriteriosdeInterconexi $\{\backslash$ unhbox \voidb@x \bgroup \let \unhbox \voidb@x \setbox

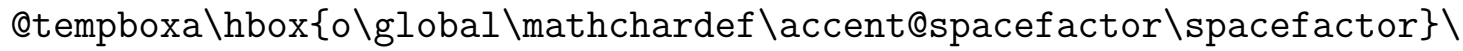
accent19o \egroup \spacefactor \accent@spacefactor\}ndeCentralesEl\{ $\backslash$ unhbox $\backslash$

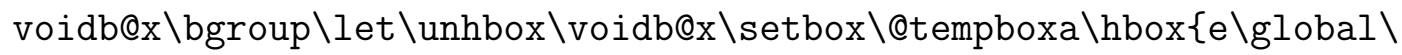
mathchardef \accent@spacefactor $\backslash$ spacefactor\} \accent19e \egroup \ spacefactor \accent@spacefactor\}ctricasyConexi\{\unhbox\voidb@x \

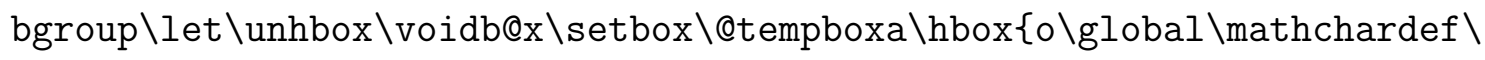
accent@spacefactor \spacefactor\}\accent19o\egroup \spacefactor \accent@ spacefactor\}ndeCentrosdeCargaDOF20150602.pdf

[62] H. Meschede, P. Holzapfel, F. Kadelbach, J. Hesselbach, Classification of global island regarding the opportunity of using RES, Applied Energy 175 (2016) 251-258. doi: 10.1016/j.apenergy.2016.05.018

URL http://linkinghub.elsevier.com/retrieve/pii/S0306261916306006

[63] D. M. Gioutsos, K. Blok, L. van Velzen, S. Moorman, Cost-optimal electricity systems with increasing renewable energy penetration for islands across the globe, Applied Energy 226 (May) (2018) 437-449. doi:10.1016/j.apenergy.2018.05.108. URL https://doi.org/10.1016/j.apenergy.2018.05.108https://linkinghub. elsevier.com/retrieve/pii/S0306261918308249

[64] M. Raza, Offshore grid control of voltage source converters for integrating offshore wind power plants, Thesis, Universitat Politècnica de Catalunya (2017).

URL https : //upcommons . upc . edu/handle/2117/114452 